\title{
Evaluation of exposures and respiratory health at two coffee roasting and packaging
}

facilities

\section{Matthew G. Duling, MS, REHS} R. Reid Harvey, DVM, MPH

Marcia L. Stanton, BS Robert B. Lawrence, MS Tia L. McClelland, MPH Randall J. Nett, MD, MPH

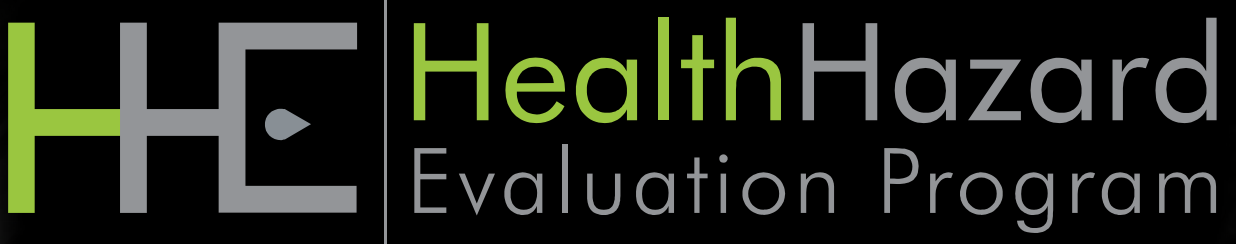

Report No. 2016-0006-3309 March 2018

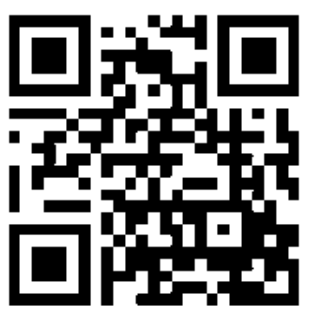

U.S. Department of Health and Human Services Centers for Disease Control and Prevention National Institute for Occupational Safety and Health

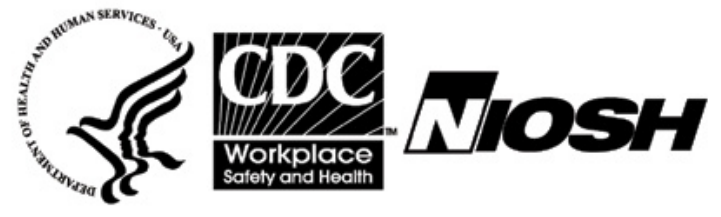




\section{Contents}

Highlights. i

Abbreviations vi

Summary 1

Introduction .......................................... 2

Background........................................... 2

Process Description ................................ 4

Methods .................................................... 5

Results ................................................ 13

Discussion ........................................... 18

Conclusions.......................................... 25

Recommendations............................ 26

Appendix A: Tables .............................. 31

References....................................... 38

Acknowledgements.......................... 47

The employer is required to post a copy of this report for 30 days at or near the workplace(s) of affected employees. The employer must take steps to ensure that the posted report is not altered, defaced, or covered by other material.

The cover photo is a close-up image of sorbent tubes, which are used by the HHE Program to measure airborne exposures. This photo is an artistic representation that may not be related to this Health Hazard Evaluation. 


\section{Highlights of this Evaluation}

The Health Hazard Evaluation Program received a request from the management of two coffee processing facilities (facility A, the northernmost facility, and facility B, the southernmost facility). Management was concerned about exposures to and health effects from diacetyl and 2,3-pentanedione during coffee roasting, packaging and grinding.

\section{What We Did}

- We visited both of the company's coffee facilities in May 2016.

- We collected full-shift (hours), task (minutes), and instantaneous (seconds) air samples to measure air levels of the alphadiketones diacetyl, 2,3-pentanedione, and 2,3-hexanedione.

- We collected roasted coffee beans to measure their emission potential for diacetyl, 2,3-pentanedione, and 2,3-hexanedione.

- We performed continuous air sampling for carbon monoxide and carbon dioxide in the roasting, packaging, and grinding areas.

- We assessed each facility's ventilation system.

- We surveyed for dampness, mold, and signs of water damage in facility A.

- We administered a health questionnaire to employees and performed breathing tests.

\section{What We Found}

Facility A:

- Four full-shift personal air samples were above the recommended exposure limit for diacetyl of 5 parts per billion. The highest concentrations of diacetyl measured as a fullshift average was 17.6 parts per billion.

- Two full-shift personal air samples were
We evaluated respiratory health and airborne exposures to alpha-diketones (diacetyl, 2,3-pentanedione, and 2,3-hexanedione), carbon monoxide, and carbon dioxide during coffee processing at two facilities. Fullshift personal air samples in the production areas of both facilities showed concentrations that were above the National Institute for Occupational Safety and Health's recommended exposure limit of 5.0 parts per billion for diacetyl, with a maximum concentration of $17.6 \mathrm{ppb}$ at facility $A$ and a maximum of $9.6 \mathrm{ppb}$ at facility B. Two full-shift personal air samples at facility A were above the recommended exposure limit for 2,3-pentanedione of 9.3 parts per billion. The highest concentrations of 2,3-pentanedione we measured as a full-shift average were $11.8 \mathrm{ppb}$ at facility $A$ and 5.3 ppb at facility $B$. In addition, air sampling during shortterm tasks identified several tasks (e.g., grinding, packaging, and moving/ blending roasted coffee beans) with higher exposures to alpha-diketones including diacetyl than other tasks. Nose and eye symptoms were the most commonly reported symptoms at both facilities. Breathing trouble and shortness of breath were among the most common lower respiratory symptom reported at both facilities. One $(10 \%)$ of ten spirometry tests were abnormal. One (9\%) of eleven participants had high exhaled nitric oxide, a marker of allergic airways inflammation. Another participant had an abnormal spirometry test (one of 10 spirometry tests). We recommend operating all fan and make-up air systems in the production spaces whenever occupied; installing local exhaust ventilation; implementing administrative controls such as modification of work practices including moving higher exposure tasks to an area with better ventilation; and training employees about workplace hazards. We also recommend instituting a medical monitoring program. 
above the recommended exposure limit for 2,3-pentanedione of 9.3 parts per billion. The highest concentration of 2,3-pentanedione measured as a full-shift average was 11.8 parts per billion.

- There was no measurable air pressure difference between the production area and the office area, meaning air did not mix between these areas. There also was no air pressure difference between the packaging/grinding area and the adjacent storage area, although multiple fans circulated air in various directions.

- Evidence of water incursion was discovered in the administration area. Further inspection in the storage area above showed water damage and evidence of incursion from holes in the outer shell of the building.

Facility $B$ :

- Six full-shift personal air samples were above the recommended exposure limit for diacetyl of 5 parts per billion. The highest concentrations of diacetyl measured as a full-shift average was 9.4 parts per billion.

- There were no full-shift personal air samples above the recommended exposure limit for 2,3-pentanedione of 9.3 parts per billion.

- When the air-conditioning system was off, there was no air pressure difference between the production area and the office area. When the air conditioning was operating, air from the production area migrated into the office area.

Both Facilities:

- Carbon dioxide and carbon monoxide levels were high inside roasted bean storage bins but generally low throughout both facilities.

- Air levels of diacetyl and 2,3-pentanedione at both facilities were higher for tasks that involved grinding roasted beans, packaging roasted beans, and moving/blending roasted beans by hand.

- Nose and eye symptoms were the most commonly reported symptoms at both facilities. Some employees reported these symptoms were caused or aggravated by green coffee beans, burlap bags, grinding coffee, or dust.

- Breathing trouble and shortness of breath were among the most commonly reported lower respiratory symptom at both facilities.

- One $(9 \%)$ of eleven medical survey participants had high exhaled nitric oxide, a marker of allergic airways inflammation. Another participant had an abnormal spirometry test (one of 10 spirometry tests).

\section{What the Employer Can Do}

\section{Both Facilities:}

- Ensure employees understand potential hazards (e.g., diacetyl, 2,3-pentanedione, carbon monoxide, carbon dioxide, green and roasted coffee dust) in the workplace and how to protect themselves. 
- Take steps to reduce employees' exposures during higher exposure tasks (grinding, packaging, and moving/blending) by:

- Limiting access to the area while higher exposure tasks are occurring.

- Relocating higher exposure tasks to a more naturally well-ventilated area.

- Installing local exhaust ventilation around higher exposure tasks.

- Continue to cover bins of roasted beans to reduce emissions of alpha-diketones, carbon monoxide, and carbon dioxide into the air.

- Encourage employees to avoid placing their heads near or inside roasted bean bins.

- Keep any openings between the production rooms and the office areas closed at all times to prevent air movement from the production areas into the office areas.

- Conduct follow-up air sampling to verify that the modifications have been effective in reducing exposures to below the recommended exposure limits.

- Make N95 disposable filtering-facepiece respirators available for voluntary use for protection against dust exposure, such as when emptying burlap bags of green beans, cleaning the roaster exhaust system of chaff, emptying the chaff containers, or cleaning the green bean storage area.

- Encourage employees to report new, worsening, or ongoing respiratory symptoms to their personal healthcare providers and to a designated individual at the workplace.

- Institute a medical monitoring program for employees who work in the production area.

Facility $A$

- Identify the sources of the moisture problem and repair to avoid future water incursion.

- Remove and replace any moisture-damaged materials.

Facility $B$

- Work with a ventilation engineer to modify the existing ventilation system to separate the reception, breakroom, and office areas from the production and warehouse areas.

- To prevent migration of production area air into the administration area, ensure adequate air-flow for temperature control is supplied to the administration area so that all doors and windows can remain closed.

\section{What Employees at Both Facilities Can Do}

- Use any local exhaust ventilation as instructed by your employer when it is installed.

- As much as possible, avoid placing your head directly above or inside roasted bean storage bins.

- Some employees may wish to use N-95 disposable filtering-facepiece respirators for some tasks, such as when emptying burlap bags of green beans into storage containers, cleaning the chaff out of the roaster exhaust system, emptying the chaff containers, or cleaning the green bean storage area. 
- Report new, persistent, or worsening respiratory symptoms to your personal healthcare provider(s) and a designated individual at your workplace.

- Participate in any personal air sampling offered by your employer.

- Participate in your employer's medical monitoring program as instructed by your employer. 
This page left intentionally blank 


\section{Abbreviations}

\begin{tabular}{|c|c|}
\hline$\mu \mathrm{m}$ & Micrometer \\
\hline$\mu \mathrm{g}$ & Microgram \\
\hline${ }^{\circ} \mathrm{F}$ & degrees Fahrenheit \\
\hline ACGIH ${ }^{\circledR}$ & American Conference of Governmental Industrial Hygienists \\
\hline $\mathrm{APF}$ & Assigned protection factor \\
\hline $\mathrm{AX}$ & Area of reactance \\
\hline $\mathrm{cfm}$ & Cubic feet per minute \\
\hline CFR & Code of Federal Regulations \\
\hline $\mathrm{CO}$ & Carbon monoxide \\
\hline $\mathrm{CO}_{2}$ & Carbon dioxide \\
\hline COPD & Chronic obstructive pulmonary disease \\
\hline DR5-R20 & The difference between resistance at 5 and 20 Hertz \\
\hline $\mathrm{FEV}_{1}$ & 1 -second forced expiratory volume \\
\hline Fres & Resonant frequency \\
\hline FVC & Forced vital capacity \\
\hline HVAC & Heating, ventilation, and air-conditioning \\
\hline $\mathrm{Hz}$ & Hertz \\
\hline $\mathrm{kPa} /(\mathrm{L} / \mathrm{s})$ & Kilopascals per liter per second \\
\hline IDLH & Immediately dangerous to life or health \\
\hline LOD & Limit of detection \\
\hline LOQ & Limit of quantitation \\
\hline $\mathrm{mg} / \mathrm{m}^{3}$ & Milligrams per cubic meter of air \\
\hline $\mathrm{mL}$ & Milliliter \\
\hline $\mathrm{mL} / \mathrm{min}$ & Milliliter per minute \\
\hline NHANES & National Health and Nutrition Examination Survey \\
\hline NIOSH & National Institute for Occupational Safety and Health \\
\hline OEL & Occupational exposure limit \\
\hline OSHA & Occupational Safety and Health Administration \\
\hline PEL & Permissible exposure limit \\
\hline ppb & Parts per billion \\
\hline ppm & Parts per million \\
\hline R5 & Resistance at 5 Hertz \\
\hline $\mathrm{R} 20$ & Resistance at 20 Hertz \\
\hline REL & Recommended exposure limit \\
\hline $\mathrm{RH}$ & Relative humidity \\
\hline SMR & Standardized morbidity ratio \\
\hline
\end{tabular}




$\begin{array}{ll}\text { STEL } & \text { Short-term exposure limit } \\ \text { TLV® } & \text { Threshold limit value } \\ \text { TVOC } & \text { Total volatile organic compound } \\ \text { TWA } & \text { Time-weighted average } \\ \text { US } & \text { United States } \\ \text { VOC } & \text { Volatile organic compound } \\ \text { X5 } & \text { Reactance at } 5 \text { Hertz }\end{array}$




\section{Summary}

In October 2015, the National Institute for Occupational Safety and Health received a management request for a health hazard evaluation at two coffee processing facilities regarding concerns about exposures to and health effects from diacetyl and 2,3-pentanedione during coffee roasting and grinding. In May 2016, we conducted a ventilation assessment, an industrial hygiene survey, and a medical survey at each coffee facility. The industrial hygiene surveys consisted of the collection of air samples and bulk samples of coffee for the analysis of diacetyl, 2,3-pentanedione, and 2,3-hexanedione. We used continuous monitoring instruments to measure total volatile organic compounds, carbon monoxide, and carbon dioxide in specific areas and during specific work tasks. The medical survey consisted of a health questionnaire and breathing tests.

\section{Facility A}

Four of 12 full-shift personal air samples taken on six employees over two days showed air levels of diacetyl above the National Institute for Occupational Safety and Health's recommended exposure limit of 5.0 parts per billion, with a maximum concentration of 17.6 parts per billion. Two of 12 full-shift personal air samples showed air levels of 2,3-pentanedione above the recommended exposure limit of $9.3 \mathrm{ppb}$ with a maximum concentration of $11.8 \mathrm{ppb}$.

\section{Facility $B$}

Six of nine full-shift personal air samples taken on five employees over two days show air levels of diacetyl above the National Institute for Occupational Safety and Health's recommended exposure limit of 5.0 parts per billion, with a maximum concentration of 9.4 parts per billion. None of the full-shift personal air samples exceeded the recommended exposure limit for 2,3-pentanedione.

We identified jobs where some work tasks resulted in relatively higher air concentrations of diacetyl than other tasks. Specifically, grinding roasted coffee beans, blending roasted coffee beans by hand, and weighing and packaging roasted coffee were associated with higher diacetyl levels.

Nose and eye symptoms were the most commonly reported symptoms at both facilities. Some employees reported their nose and eye symptoms were caused or aggravated by green coffee beans, burlap bags, grinding coffee, or dust. Breathing trouble or shortness of breath were among the most commonly reported lower respiratory symptom at both facilities. One (9\%) of eleven participants had high exhaled nitric oxide, a marker of allergic airways inflammation. Another participant had an abnormal spirometry test (one of 10 spirometry tests). We recommend training employees about work-place hazards and the use of respiratory protection. We also recommend a medical monitoring program to identify any employees who may be developing work-related lung disease (e.g., asthma, obliterative bronchiolitis) and to help management prioritize interventions to prevent occupational lung disease. 


\section{Introduction}

In October 2015, the National Institute for Occupational Safety and Health (NIOSH) received a management request for a health hazard evaluation at two coffee roasting and packaging facilities regarding potential worker exposure to diacetyl and 2,3-pentanedione during coffee processing. In May 2016, we visited the facilities to learn more about coffee processing at these facilities and to conduct industrial hygiene and medical surveys.

\section{Background}

\section{Diacetyl and 2,3-Pentanedione}

Diacetyl (2,3-butanedione) and 2,3-pentanedione (acetyl propionyl) are volatile organic compounds (VOCs) known as alpha-diketones that are added as ingredients in food flavorings used in some food products such as microwave popcorn, bakery mixes, and flavored coffee [Day et al. 2011; Kanwal et al. 2006; Bailey et al. 2015]. Diacetyl, 2,3-pentanedione, other VOCs, and gases such as carbon monoxide (CO) and carbon dioxide $\left(\mathrm{CO}_{2}\right)$ are naturally produced and released during the coffee roasting process [Duling et al. 2016; Raffel and Thompson 2013; Daglia et al. 2007; Nishimura et al. 2003; Newton 2002]. Grinding roasted coffee beans produces a greater surface area for off-gassing (sometimes called degassing) of these compounds [Akiyama et al. 2003]. Often, coffee roasting facilities package newly roasted coffee in permeable bags or in bags fitted with one-way valves to allow the coffee to off-gas after it is packaged. Sometimes, newly roasted coffee is placed in bins or containers and allowed to off-gas before packaging.

NIOSH has recommended exposure limits (RELs) for diacetyl and 2,3-pentanedione in workplace air (Table 1) [NIOSH 2016]. The NIOSH objective in establishing RELs for diacetyl and 2,3-pentanedione is to reduce the risk of respiratory impairment (decreased lung function) and the severe irreversible lung disease obliterative bronchiolitis associated with occupational exposure to these chemicals. NIOSH RELs are intended to protect workers exposed to diacetyl or 2,3-pentanedione for a 45-year working lifetime. The REL for diacetyl is based on a quantitative risk assessment which necessarily contains assumptions and some uncertainty. Analytical limitations current at the time were taken into consideration in setting the REL for 2,3-pentanedione. The RELs should be used as a guideline to indicate when steps should be taken to reduce exposures in the workplace.

These exposure limits and the accompanying recommendations for control of exposures were derived from a risk assessment of flavoring-exposed workers. At an exposure equal to the diacetyl REL, the risk of adverse health effects is low. NIOSH estimated that less than 1 in 1,000 workers exposed to diacetyl levels of 5 parts per billion (ppb) as a timeweighted average (TWA) for 8 hours a day, 40 hours a week for a 45 -year working lifetime would develop reduced lung function (defined as forced expiratory volume in one second $\left[\mathrm{FEV}_{1}\right]$ below the $5^{\text {th }}$ percentile) as a result of that exposure. NIOSH predicted that around 1 in 10,000 workers exposed to diacetyl at $5 \mathrm{ppb}$ for a 45 -year working lifetime would develop more severe lung function reduction $\left(\mathrm{FEV}_{1}\right.$ below $60 \%$ predicted, defined as at 
least moderately severe by the American Thoracic Society [Pellegrino et al. 2005]). Workers exposed for less time would be at lower risk for adverse lung effects.

\section{2,3-Hexanedione}

2,3-Hexanedione is also an alpha-diketone that is sometimes used as a substitute for diacetyl and is produced naturally during coffee roasting. In a study using animals, there was some evidence that 2,3-hexanedione might also damage the lungs, but it appeared to be less toxic than diacetyl and 2,3-pentanedione [Morgan et al. 2016]. There are no established occupational exposure limits for 2,3-hexanedione.

\section{Carbon Monoxide and Carbon Dioxide}

$\mathrm{CO}$ and $\mathrm{CO}_{2}$ are gases produced by combustion. They are also produced as a result of reactions that take place during coffee roasting. These gases are released during and after roasting and grinding by a process called off-gassing [Anderson et al. 2003]. High exposures to $\mathrm{CO}$ and $\mathrm{CO}_{2}$ can cause headache, dizziness, fatigue, nausea, confusion, rapid breathing, impaired consciousness, coma, and death [Newton 2002; Nishimura et al. 2003; Langford 2005; CDC 2013a; Raffel and Thompson 2013; Rose et al. 2017]. Occupational exposure limits for $\mathrm{CO}$ and $\mathrm{CO}_{2}$ are listed in Table 1.

\section{Obliterative Bronchiolitis}

Obliterative bronchiolitis is a serious, often disabling, lung disease that involves scarring of the very small airways (i.e., bronchioles). Symptoms of this disease may include cough, shortness of breath on exertion, and/or wheeze, that do not typically improve away from work [NIOSH 2012]. Occupational obliterative bronchiolitis has been identified in flavoring manufacturing workers and microwave popcorn workers who worked with flavoring chemicals or butter flavorings [Kreiss 2013; Kim et al. 2010; Kanwal et al. 2006]. It has also been identified in employees at a coffee roasting and packaging facility that produced unflavored and flavored coffee [CDC 2013b]. A NIOSH health hazard evaluation at that facility found diacetyl and 2,3-pentanedione concentrations in the air that were elevated and identified three sources: 1) flavoring chemicals added to roasted coffee beans in the flavoring area; 2) grinding unflavored roasted coffee beans and packaging unflavored ground and whole bean roasted coffee in a distinct area of the facility, and 3) storing roasted coffee in hoppers, on a mezzanine above the grinding/packaging process, to off-gas [Duling et al. 2016]. At the time of the health hazard evaluation, workers had excess shortness of breath and obstruction on spirometry, both consistent with undiagnosed lung disease. Respiratory illness was associated with exposure and not limited to the flavoring areas [Bailey et al. 2015]. However, all workers who were diagnosed with obliterative bronchiolitis had worked in the flavoring area. To date, no cases of obliterative bronchiolitis have been reported in workers at coffee roasting and packaging facilities that produce only unflavored coffee.

\section{Work-related Asthma}

Work-related asthma refers to asthma that is brought on by ("occupational asthma") or made worse by ("work-exacerbated asthma" or "work-aggravated asthma") workplace exposures [Tarlo 2016; Tarlo and Lemiere 2014; OSHA 2014; Henneberger et al. 2011]. Work-related asthma includes asthma due to sensitizers, which cause disease through immune (allergic) 
mechanisms, and asthma due to irritants, which cause disease through non-immune mechanisms. Symptoms of work-related asthma include episodic shortness of breath, cough, wheeze, and chest tightness. The symptoms may begin early in a work shift, towards the end of a shift, or hours after a shift. They generally, but do not always, improve or remit during periods away from work, such as on weekends or holidays.

Green and roasted coffee dust and castor beans (from cross-contamination of bags used to transport coffee) are known risk factors for occupational asthma [Figley and Rawling 1950; Karr et al. 1978; Zuskin et al. 1979, 1985; Thomas et al. 1991]. Persons who become sensitized (develop an immune reaction) to coffee dust can subsequently react to relatively low concentrations in the air. Others may experience irritant-type symptoms from exposure to coffee dust [Oldenburg et al. 2009].

\section{Process Description}

The production area of facility A (the northernmost facility) was approximately 800 square feet with an adjacent $1,400+$ square feet of office space and an additional $400+$ square feet of storage. This facility employed six workers. Three employees were involved in various administrative tasks which included accounts receivable, customer service, inventory control, graphic design, sales, and farmer relations. The remaining three employees were responsible for activities specific to the coffee roasting process.

The production area of facility B (the southernmost facility) was approximately 1200 square feet with an adjacent $700+$ square feet of office space and an additional 600+ square feet of storage. This facility employed five workers. Two of the employees were involved in various administrative tasks which included accounts receivable, customer service, inventory control, graphic design, sales and farmer relations. The remaining employees were responsible for activities specific to the coffee roasting process. This process description describes the processes at each facility as of May 2016.

The coffee roasting process at both facilities involved four main steps: receiving organic green beans (unroasted coffee beans), roasting green beans, weighing and packaging of roasted beans (whole and ground), and shipping or delivery of final product to individual consumers, food cooperatives, and markets.

Green beans were received in burlap bags from various countries around the world including Colombia, Guatemala, Mexico, and Honduras. Upon arrival at the facility, pallets of green beans were stored in the climate controlled roasting room until needed for roasting. To prepare a batch for roasting, a roaster operator loaded the green beans from the bag into a container equipped with a scale to achieve the proper weight needed for a roast. The green beans were then vacuum transferred into the roaster hopper until the desired amount for that particular roast had been loaded. The green beans were automatically conveyed from the hopper into the roasting drum and heated at a specific temperature for a specific time period until the desired roast was achieved. At the end of each roast cycle, the roasted beans were 
then emptied into a down-draft cooling bin where they were slowly mixed to accelerate cooling. A roaster operator monitored the roasting equipment throughout the roasting process. After being cooled, the roasted beans were emptied from the cooling bin into storage containers. These containers were then manually moved by the roaster operator to a storage shelf in the packaging/grinding room and labeled with the date, origin of bean, and type of roast.

A production employee scooped roasted beans from the storage containers to obtain the desired amount for either grinding or packaging. For whole-bean coffee, the appropriate amount of roasted beans was hand scooped from the storage containers to fill the packaging order: one pound, two pounds, or five pounds. For grinding operations, individual, preweighed packages of roasted whole beans were emptied into a grinder. The grinder was adjusted for type of grind (coarse, medium, fine). Packages of both whole and ground coffee were heat-sealed and placed on storage shelves or immediately packed for shipment or local delivery.

\section{Quality Control}

The company took measures to ensure the quality of green beans and roasts. Green beans in storage were monitored over time as they aged and roasting specifications were adjusted to account for the aging of the green beans. Roasted beans were packed in the order they were roasted to ensure freshness.

\section{Cleaning Activities}

Various cleaning techniques were used throughout the production areas. Sweeping, wiping (dry and wet cloths), and vacuum cleaning methods were used for the production spaces and equipment. Sweeping was performed on the production floors; wiping was performed on table tops and equipment surfaces and to remove coffee bean dust from surfaces and equipment.

\section{Methods}

We visited the coffee facilities in May 2016. At each facility, we held an opening meeting with all employees and management, performed a ventilation assessment, and collected air samples. We also conducted medical surveys at each facility. At the conclusion of each site visit, we held a closing meeting with management and employees.

We had the following objectives for the health hazard evaluation:

1. Measure employees' exposure to diacetyl, 2,3-pentanedione, and 2,3-hexanedione during coffee processing;

2. Identify process areas or work tasks associated with emissions of diacetyl, 2,3-pentanedione, and 2,3-hexanedione;

3. Measure levels of $\mathrm{CO}$ and $\mathrm{CO}_{2}$ throughout the facility; 
4. Assess ventilation systems and their effect on exposure levels;

5. Determine if employees had mucous membrane, respiratory, or systemic symptoms and the proportion of those symptoms that were work-related or aggravated by work;

6. Determine if employees had abnormal lung function tests; and

7. Compare employees' prevalence of respiratory symptoms and healthcare providerdiagnosed asthma to expected levels based on general population values.

\section{Industrial Hygiene Survey}

Sampling Times for Alpha-Diketones

We designed the sampling strategy to assess full-shift exposures and to identify tasks and processes that were the greatest contributors to worker exposure to alpha-diketones. Sampling was conducted on May 23 and 242016 at facility A and May 25 and 262016 at facility B. For diacetyl, 2,3-pentanedione, and 2,3-hexanedione, air samples were collected over seconds, minutes, and hours. Samples collected over hours can help determine average concentrations that can be compared to the NIOSH RELs for diacetyl and 2,3-pentanedione. These average concentrations might not tell us about short-term peak exposures that could be relevant to respiratory health, particularly when tasks are repeated multiple times per day. Therefore, during particular tasks, we collected air samples over several minutes. We also conducted instantaneous sampling over seconds to help identify point sources of alphadiketones.

Employees that participated in air sampling were given the opportunity to request their individual air sampling results.

Air Sampling and Analysis Using Modified Occupational Safety and Health Administration (OSHA) Methods 1013/1016

We collected personal and area air samples for diacetyl, 2,3-pentanedione, and 2,3-hexanedione on silica gel sorbent tubes during the industrial hygiene surveys at two facilities over two days at each facility. The samples were collected and analyzed according to the modified OSHA sampling and analytical Methods 1013/1016 [OSHA 2008; OSHA 2010; LeBouf and Simmons 2017]. In accordance with the two methods, two glass silica gel sorbent tubes were connected by a piece of tubing and inserted into a protective, lightblocking cover. The tubes were connected in series to a sampling pump pulling air through the tubes at a flow rate of 50 milliliters per minute $(\mathrm{mL} / \mathrm{min})$. The sampling setup was attached to an employee's breathing zone or placed in an area basket in various locations throughout the facility. For full-shift sampling, we collected two consecutive 3-hour samples and calculated the TWA concentration from the two samples, assuming that the total 6-hour monitoring results reflected a full work shift (8-hour) TWA exposure. Although this may introduce some error, it is a conservative approach that is more protective of employees than the alternative assumption of no exposure during the last two hours of the shift. We refer to these samples as "full-shift samples" throughout this report. We also collected short-term 
task-based samples in the same manner, but the sampling pump flow rate was $200 \mathrm{~mL} / \mathrm{min}$ as detailed in OSHA Methods 1013 and 1016 [OSHA 2008; 2010]. Sampling times were dependent on the duration of the task being performed. Employees that participated in air sampling were given the opportunity to request their individual air sampling results.

Analyses of the samples were performed in the NIOSH Respiratory Health Division's Organics Laboratory. The samples were extracted for one hour in 95\% ethanol: 5\% water containing 3-pentanone as an internal standard. Samples from both visits were analyzed using an Agilent 7890/7001 gas chromatograph/mass spectrometer system operated in selected ion monitoring mode for increased sensitivity compared to the traditional flame ionization detector used in OSHA Methods 1013 and 1016 [LeBouf and Simmons 2017].

A limit of detection (LOD) is the lowest mass that an instrument can detect above background and is a criteria used to determine whether to report a result from a sample. The LODs were $0.01 \mu \mathrm{g} /$ sample for diacetyl, $0.012 \mu \mathrm{g} /$ sample for 2,3-pentanedione, and $0.02 \mu \mathrm{g} /$ sample for 2,3-hexanedione; these were based on variability of low-level spiked samples. These equate to $0.32 \mathrm{ppb}$ for diacetyl, $0.33 \mathrm{ppb}$ for 2,3-pentanedione, and $0.48 \mathrm{ppb}$ for 2,3-hexanedione for a typical full-shift TWA air sample. The LODs for task samples are generally higher than typical LOD values for full-shift samples since the air volumes collected during task samples are lower. When the values presented in the report are from samples below the LOD they are denoted by a " $<$ " symbol.

\section{Air Sampling and Analysis Using Evacuated Canisters}

We collected instantaneous task-based and source air samples for VOCs including diacetyl, 2,3-pentanedione, and 2,3-hexanedione using evacuated canisters. The evacuated canister sampling setup consisted of a 450-mL evacuated canister equipped with an instantaneous flow controller that was designed for a short sampling duration (less than 30 seconds). Instantaneous samples were taken by opening the evacuated canister to grab a sample of air to help identify point sources of alpha-diketones. For task-based air samples, a NIOSH employee placed the inlet of the flow controller by the employee's personal breathing zone as they performed their work task to replicate exposure. For source air samples, a NIOSH employee placed the inlet of the flow controller directly at the source of interest.

The canister air samples were analyzed using a pre-concentrator/gas chromatograph/ mass spectrometer system pursuant to a published method validation study [LeBouf et al. 2012], with the following modifications: the pre-concentrator was a Model 7200 (Entech Instruments, Inc., Simi Valley, CA), and six additional compounds, diacetyl, 2,3-pentanedione, 2,3-hexanedione, acetaldehyde, acetonitrile, and styrene, were included. At present, this canister method is partially validated [LeBouf et al. 2012] and not considered the standard method. For the first visit, the LODs were $0.84 \mathrm{ppb}$ for diacetyl, $1.38 \mathrm{ppb}$ for 2,3-pentanedione, and $2.49 \mathrm{ppb}$ for 2,3-hexanedione based on a three-times dilution factor, which is typical for restricted flow controller samplers. For the second visit, the LODs were $0.78 \mathrm{ppb}$ for diacetyl, $1.08 \mathrm{ppb}$ for 2,3-pentanedione, and $1.92 \mathrm{ppb}$ for 2,3-hexanedione based on a three-times dilution factor. However, LODs are dependent on the pressure inside each canister after the samples have been collected, and they may be higher or lower than typical LOD values. 


\section{Bulk Sampling and Headspace Analysis}

We used 50-mL sterile polypropylene centrifuge tubes to collect approximately $40-\mathrm{mL}$ bulk samples of roasted coffees (whole bean and ground). For headspace analysis of alpha-diketones, we transferred 1 gram of solid bulk material into a sealed $40-\mathrm{mL}$ amber volatile organic analysis vial and let it rest for 24 hours at room temperature $\left(70^{\circ} \mathrm{F}\right)$ in the laboratory. Then $2 \mathrm{~mL}$ of headspace air was transferred to a $450-\mathrm{mL}$ canister and pressurized to approximately 1.5 times atmospheric pressure. Using the canister analysis system, the concentrations were calculated in ppb of analytes in the headspace as an indicator of emission potential.

\section{Real-time (Continuous) Air Sampling}

We used RAE Systems (San Jose, CA) ppbRAE 3000 (Model \#PGM-7340) monitors to measure concentrations of total volatile organic compounds (TVOCs) in the air. The ppbRAE has a non-specific photoionization detector that responds to chemicals with ionization potentials below the energy of the lamp. This sampling was conducted to identify areas where coffee could be releasing TVOCs. Areas where higher concentrations of TVOCs are measured may benefit from further sampling to characterize specific exposures to alphadiketones. We also collected real-time measurements of $\mathrm{CO}_{2}, \mathrm{CO}$, temperature, and relative humidity (RH) using TSI Incorporated (Shoreview, MN) VelociCalc Model 9555-X MultiFunction Ventilation Meters equipped with Model 982 IAQ probes.

\section{Musty Odor Assessment}

In facility $\mathrm{A}$, in response to musty odors in the office area, we visually inspected for water incursion and mold growth in areas above ceiling tiles and in a second floor storage area above the office areas. We also inspected for sources of water incursion in the metal roof above the office area.

\section{Exposure Limits}

We utilize mandatory (legally enforceable) and recommended occupational exposure limits (OELs) when evaluating workplace hazards. OELs have been developed by federal agencies and safety and health organizations to prevent adverse health effects from workplace exposures.

\section{Occupational Safety and Health Administration (OSHA) [Mandatory]}

The U.S. Department of Labor's OSHA permissible exposure limits (PELs) are legal limits that are enforceable in workplaces covered under the Occupational Safety and Health Act. OSHA PELs represent the legal maximum for a TWA exposure to a physical or chemical agent over a work shift [OSHA 2017]. OSHA short-term exposure limits (STELs) are the legal maximum average exposure for a 15-minute time period. Some chemicals also have an OSHA ceiling value which represent levels that must not be exceeded at any time. Currently, there are no PELs for diacetyl, 2,3-pentanedione, or 2,3-hexanedione. For substances for which an OSHA PEL has not been issued, violation of the OSHA General Duty Clause can be considered using available occupational exposure references and recommendations [OSHA 1993; OSHA 2003], such as the American Conference of Governmental Industrial Hygienists (ACGIH) Threshold Limit Values $\left(\mathrm{TLVs}^{\circledR}\right)$ and NIOSH RELs. 
American Conference of Governmental Industrial Hygienists (ACGIH) [Recommended]

ACGIH is a professional, not-for-profit scientific association that reviews existing published, peer-reviewed scientific literature and publishes recommendations for levels of substances in air based on an 8-hour workday and 40-hour workweek. These recommendations are called threshold limit values (TLVs) [ACGIH 2017a]. ACGIH TLVs are not standards; they are health-based guidelines derived from scientific and toxicological information. ACGIH provides TLV-TWA guidelines that are levels that should not be exceeded during any 8-hour workday of a 40-hour workweek. ACGIH also provides TLV-STEL guidelines which are 15-minute exposure levels that should not be exceeded during a workday. Exposures above the TLV-TWA but less than the TLV-STEL should be (1) less than 15 minutes, (2) occur no more than four times a day, and (3) be at least 60 minutes between exposures [ACGIH 2017a]. Additionally, ACGIH provides TLV-Ceiling values which are levels that should not be exceeded at any time during a work shift. The ACGIH TLV-TWA for diacetyl is 10 $\mathrm{ppb}$. The TLV-STEL for diacetyl is $20 \mathrm{ppb}$. Currently, there is no TLV-TWA or TLV-STEL for 2,3-pentanedione. ACGIH has placed 2,3-pentanedione on the 2017 list of Chemical Substances and Other Issues Under Study [ACGIH 2017b].

National Institute for Occupational Safety and Health (NIOSH) [Recommended] NIOSH provides RELs as TWA concentrations that should not be exceeded over an 8 or 10-hour work shift, during a 40-hour workweek [NIOSH 2010]. RELs are intended to be protective over a 45-year working lifetime. NIOSH also provides STELs which are 15-minute TWA exposures that should not be exceeded at any time during a workday [NIOSH 2010]. Some chemicals have ceiling values which are concentrations that should not be exceeded at any time [NIOSH 2010]. For some chemicals, NIOSH has established an Immediately Dangerous to Life or Health (IDLH) value. An IDLH value is a concentration of an air contaminant that can cause death or immediate or delayed permanent adverse health effects, or prevent escape from such an environment. Currently, NIOSH has RELs and STELs for diacetyl and 2,3-pentanedione. NIOSH does not have a REL or a STEL for 2,3-hexanedione. NIOSH does not have ceiling limits or IDLH values for diacetyl, 2,3-pentanedione, or 2,3-hexanedione.

For diacetyl and 2,3-pentanedione, the NIOSH RELs are $5.0 \mathrm{ppb}$ and $9.3 \mathrm{ppb}$, respectively, as a TWA for up to an 8-hour workday during a 40-hour workweek (Table 1). The NIOSH STELs are $25 \mathrm{ppb}$ for diacetyl and $31 \mathrm{ppb}$ for 2,3-pentanedione [NIOSH 2016]. The NIOSH exposure limits do not differentiate between natural and synthetic chemical origin of diacetyl or 2,3-pentanedione. Although the NIOSH exposure limit for 2,3-pentanedione is above that of diacetyl, 2,3-pentanedione has been shown to be as hazardous as diacetyl [Hubbs et al. 2012; Morgan et al. 2012]. The NIOSH REL is higher for 2,3-pentanedione than for diacetyl largely because analytic measures were not available in a validated OSHA method to detect 2,3-pentanedione at lower levels. The hazard potential probably increases when these chemicals occur in combination with each other; having exposure to chemicals with the same functional alpha-diketone group and effect on the same system or organ (e.g., lungs) can result in additive effects [ACGIH 2016]. In addition to the REL, NIOSH also recommends an action level for diacetyl of $2.6 \mathrm{ppb}$ to be used with exposure monitoring in an effort to ensure employee exposures are routinely below the diacetyl REL. When exposures exceed the 
action level, employers should take corrective action (i.e., determine the source of exposure, identify methods for controlling exposure) to ensure that exposures are maintained below the NIOSH REL for diacetyl [NIOSH 2016].

Table 1. Personal exposure limits for compounds sampled for during the NIOSH surveys, May 2016.

\begin{tabular}{|l|c|c|c|c|c|c|}
\hline \multirow{2}{*}{ Compound } & OSHA* & \multicolumn{2}{c|}{ ACGIH } & \multicolumn{3}{c|}{ NIOSH } \\
\cline { 2 - 7 } & PEL & TLV & STEL & REL & STEL & IDLH \\
\hline Diacetyl & - & $10 \mathrm{ppb}$ & $20 \mathrm{ppb}$ & $5.0 \mathrm{ppb} \dagger$ & $25 \mathrm{ppb}$ & - \\
\hline 2,3-Pentanedione & - & - & - & $9.3 \mathrm{ppb} \dagger$ & $31 \mathrm{ppb}$ & - \\
\hline 2,3-Hexanedione & - & - & - & - & - & - \\
\hline Carbon dioxide $\S$ & $5,000 \mathrm{ppm}$ & $5,000 \mathrm{ppm}$ & $30,000 \mathrm{ppm}$ & $5,000 \mathrm{ppm}$ & $30,000 \mathrm{ppm}$ & $40,000 \mathrm{ppm}$ \\
\hline Carbon monoxide $\S$ & $50 \mathrm{ppm}$ & $25 \mathrm{ppm}$ & - & $35 \mathrm{ppm}$ & $\begin{array}{c}200 \mathrm{ppm} \\
\text { (ceiling limit) }\end{array}$ & $1,200 \mathrm{ppm}$ \\
\hline
\end{tabular}

Note: OSHA=Occupational Safety and Health Administration; ACGIH=American Conference of Governmental Industrial Hygienists; NIOSH=National Institute for Occupational Safety and Health; $P E L=$ permissible exposure limit; $S T E L=$ short-term exposure limit; $T L V=$ threshold limit value; $R E L=$ recommended exposure limit; IDLH=immediately dangerous to life or health; $p p b=$ parts per billion; ppm=parts per million; "_"=no exposure limit available.

*There are no OSHA STELs for the compounds in the table.

$\dagger$ The NIOSH RELs for diacetyl and 2,3-pentanedione are time-weighted averages for up to an 8-hour day, during a 40-hour workweek.

§OSHA and NIOSH limits are designed for occupational exposure measurements in manufacturing and other trades that have potential sources of carbon dioxide or carbon monoxide (e.g., coffee roasting, welding, vehicle exhaust, diesel engine exhaust). Typical levels of carbon monoxide in offices are $0-5$ ppm. In office settings, carbon dioxide generally should not be greater than $700 \mathrm{ppm}$ above outdoor carbon dioxide levels; this typically corresponds to indoor concentrations below $1200 \mathrm{ppm}$.

qThis is the NIOSH ceiling exposure limit for carbon monoxide. A ceiling concentration should not be exceeded at any time.

\section{Ventilation Assessments}

We collected physical measurements of all rooms and calculated approximate room volumes. Where possible, air flow measurements of supply vents and exhaust outlets were taken using a TSI (TSI Incorporated, St. Paul, MN) Accubalance Plus Model 8373 Air Capture Hood or a TSI VelociCalc Plus Model 8324 (Shoreview, MN) Rotating Vane Anemometer, depending on which was most appropriate for the ventilation component being measured. Differential pressure measurements between adjacent spaces were also taken under various ventilation scenarios using an Energy Conservatory (Minneapolis, MN) DG-500 Pressure Gauge.

\section{NIOSH Medical Survey}

\section{Participants}

We invited all current employees to participate in the medical surveys that occurred on May 24, 2016 at facility B and May 25, 2016 at facility A. Participation was voluntary; written informed consent was obtained from each participant before testing. The survey included, in the order performed, a medical and work history questionnaire, quantification of exhaled nitric oxide, impulse oscillometry, spirometry, and if indicated the administration of a bronchodilator with repeat impulse oscillometry and spirometry. We mailed participants their individual reports explaining their breathing test results and recommended each participant provide the information to their personal physician. 


\section{Questionnaire}

We used an interviewer-administered computerized questionnaire to ascertain symptoms and diagnoses, work history at these coffee process facilities and other coffee or flavoring companies, and cigarette smoking history. Questions on respiratory health were derived from five standardized questionnaires - the European Community Respiratory Health Survey [Burney et al. 1994; ECRHS 2014], the American Thoracic Society adult respiratory questionnaire (ATS-DLD-78) [Ferris 1978], the International Union Against Tuberculosis and Lung Disease [Burney and Chinn 1987; Burney at al. 1989], and the Third National Health and Nutrition Examination Survey (NHANES) [CDC 1996] and NHANES 2007-2012 questionnaires [CDC 2018]. Some of the questions appeared on more than one of the standardized questionnaires. We also supplemented our questionnaire with additional respiratory and systemic symptom questions.

\section{Spirometry}

The purpose of the spirometry test was to determine a person's ability to move air out of their lungs. Test results were compared to expected normal values. The test included three measurements or calculations: 1) forced vital capacity (FVC) (the total amount of air the participant can forcefully blow out after taking a deep breath), 2) $\mathrm{FEV}_{1}$ (the amount of air that the participant can blow out in the first second of exhaling), and 3 ) the ratio of $F E V_{1}$ to FVC. We used American Thoracic Society criteria for acceptability and repeatability [Miller et al. 2005].

We used a volume spirometer (dry rolling seal spirometer) to measure exhaled air volume and flow rates. We used equations for predicted values and lower limits of normal derived from NHANES III data to define abnormal spirometry [Hankinson et al. 1999]. We defined obstruction as an $\mathrm{FEV}_{1} / \mathrm{FVC}$ ratio less than the lower limit of normal with $\mathrm{FEV}_{1}$ less than the lower limit of normal; restriction as a normal $\mathrm{FEV}_{1} / \mathrm{FVC}$ ratio with $\mathrm{FVC}$ less than the lower limit of normal; and mixed obstruction and restriction as having $\mathrm{FEV}_{1}, \mathrm{FVC}$, and $\mathrm{FEV}_{1} / \mathrm{FVC}$ ratio all less than the lower limit of normal. We used the $\mathrm{FEV}_{1}$ percent predicted to categorize such abnormalities as mild, moderate, moderately severe, severe, or very severe [Pellegrino et al. 2005].

\section{Impulse Oscillometry}

Many occupational lung diseases (e.g., chronic obstructive pulmonary disease (COPD), asthma) involve the small airways; however, this part of the lung is difficult to evaluate noninvasively. Oscillometry is a helpful technology to understand the effects of occupational exposures on the small airways. There are no contraindications to the test as this test is conducted using regular breathing and does not require a forceful exhalation [Smith et al. 2005]. Spirometry can be normal despite respiratory symptoms or evidence of small airways disease on lung biopsy [King et al. 2011; Oppenheimer et al. 2007]; therefore, oscillometry results complement spirometry and can be used when spirometry is not possible because of a contraindication.

We used an impulse oscillometry machine (CareFusion Corp., San Diego, CA) to measure resistance $(\mathrm{R})$, the energy required to propagate the pressure wave through the airways, 
and reactance $(\mathrm{X})$, which reflects the viscoelastic properties of the respiratory system. The impulse oscillometry testing machine sends sound waves called pressure oscillations at different frequencies (e.g., 5 Hertz and 20 Hertz) into the airways to measure how airways respond to these small pressures. The test calculates 1) the airway resistance at different frequencies including 5 Hertz (R5) and 20 Hertz (R20), and the difference between R5 and R20 (DR5-R20); 2) the reactance at different frequencies including 5 Hertz (X5); 3) resonance frequency (Fres) which is the frequency where there is no airway reactance; and 4) the total reactance (AX) at all frequencies between 5 Hertz and the Fres. The predicted values for $\mathrm{R}$ and $\mathrm{X}$ were based on sex and age according to reference values recommended by the manufacturer [Vogel and Smidt 1994]. R5 was considered abnormal (elevated) if the measured value was equal to or greater than 140 percent of the predicted R5. X5 was considered abnormal (decreased) if the value of the predicted X5 minus measured X5 was equal to or greater than 0.15 kilopascals per liter per second $(\mathrm{kPa} /(\mathrm{L} / \mathrm{s}))$. DR5-R20 values greater than $30 \%$ were considered abnormal and evidence of frequency dependence [Smith 2015]. We interpreted the test as normal if both the R5 and X5 were normal [Smith 2015]. We defined possible large (central) airways abnormality as a normal X5 and elevated R5 with no evidence of frequency dependence. We defined a possible small airways abnormality if there was evidence of frequency dependence and/or a decreased X5 with or without an elevated R5. We defined possible combined small (peripheral) and large (central airways) abnormality as a decreased X5 and elevated R5 with no evidence of frequency dependence.

\section{Bronchodilator Reversibility Testing for Impulse Oscillometry and Spirometry}

If a participant had abnormal impulse oscillometry or spirometry, we repeated both tests after the participant received a bronchodilator inhaler medication (i.e., albuterol), which can open the airways in some individuals (e.g., asthmatics). For oscillometry, we defined reversibility (improvement) after bronchodilator administration as a decrease of at least $20 \%$ of either Fres or R5 or a decrease of $40 \%$ for AX. For spirometry, we defined reversibility (improvement) as increases of at least $12 \%$ and $200 \mathrm{~mL}$ for either $\mathrm{FEV}_{1}$ or $\mathrm{FVC}$ after bronchodilator administration.

\section{Fractional Exhaled Nitric Oxide (FeNO)}

We used the NIOX MINO ${ }^{\circledR}$ device (Aerocrine Inc., Morrisville, NC) to measure the amount of nitric oxide in the air the participant breathed out. Nitric oxide is a gas that is produced by the airways, and elevated levels can be a sign of eosinophilic airway inflammation in asthma [Dweik et al. 2011]. In adults, fractional nitric oxide concentration in exhaled breath levels above $50 \mathrm{ppb}$ are considered elevated. In adults with asthma, elevated levels may indicate that their asthma is uncontrolled [Dweik et al. 2011].

\section{Statistical Analysis}

\section{Industrial Hygiene Survey and Ventilation Assessment}

We performed analyses using Excel (Microsoft ${ }^{\circledR}$, Redmond, WA) and SAS version 9.3 (SAS Institute Inc., Cary, NC). We created summary statistics by work area location, job title, and task. When the values presented in the report are from samples below the LOD they are denoted by a "<" symbol. 


\section{Medical Survey}

We calculated frequencies and standardized morbidity ratios (SMRs) and their associated 95\% confidence intervals (CI) using SAS version 9.3 (Cary, NC). The SMRs compared prevalences of symptoms and diagnoses among participants to expected prevalences of a sample of the general population reflected in the NHANES III (1988-1994) or NHANES 2007-2012, adjusting for sex, race/ethnicity, age (less than 40 years old or 40 years or greater), and cigarette smoking categories (ever/never). For comparisons to the U.S. population, we used the most recent NHANES survey available for the specific comparisons. The small number of participants limits the conclusions that can be drawn from these analyses. Nonetheless, we report these results to provide some context for how commonly these symptoms and diagnoses are reported by adults in the general population.

\section{Results}

All results tables are located in Appendix A.

\section{Industrial Hygiene Survey}

Personal and Area Full-shift Air Sampling Results

\section{OSHA Methods 1013/1016}

Facility A: Table A1 presents the personal and area full-shift air sampling results from our visit to facility A. We collected 12 personal samples on six workers and 17 area full-shift air samples. Four personal air samples were above the NIOSH REL for diacetyl of $5.0 \mathrm{ppb}$, and two were above the NIOSH REL for 2,3-pentanedione of $9.3 \mathrm{ppb}$. Employees in packaging had the highest exposure to diacetyl (17.6 ppb) and 2,3-pentanedione (11.8 ppb).

Area samples were collected in seven locations throughout the facility. Area samples in grinding, weigh/blend, and roasting showed the highest concentrations of diacetyl, 25.1 ppb, $17.3 \mathrm{ppb}$, and $10.0 \mathrm{ppb}$, respectively. All area samples taken in grinding and packaging exceeded the NIOSH REL for diacetyl. Grinding, and weigh blend also showed the highest concentrations of 2,3-pentanedione: $15.5 \mathrm{ppb}, 10.8 \mathrm{ppb}$, and $5.8 \mathrm{ppb}$. We note NIOSH RELs are intended to be directly compared with personal full-shift measurements; therefore, an area air sample exceeding a NIOSH REL is only an indication of potential personal exposures.

For most personal and area air samples, the concentration of 2,3-hexanedione was below the LOD. The only samples with results above the LOD for 2,3-hexanedione were three personal samples in packaging and five area samples (two in grinding, and one each in packaging, weigh/blend, and roasting).

Facility B: Table A2 presents the personal and area full-shift air sampling results from our visit to facility B. We collected nine personal samples on five workers and 14 area fullshift air samples. Six (67\%) of the nine personal air samples exceeded the NIOSH REL for diacetyl of $5.0 \mathrm{ppb}$, and all were below the NIOSH REL for 2,3-pentanedione of $9.3 \mathrm{ppb}$. 
Overall, employees working in the production area had the highest exposure to diacetyl (range: $4.9 \mathrm{ppb}-9.4 \mathrm{ppb}$ ) and 2,3-pentanedione (range: $2.6 \mathrm{ppb}-5.3 \mathrm{ppb}$ ). Two of the three office area employee samples exceeded the NIOSH REL for diacetyl (range: $2.3 \mathrm{ppb}-6.5$ $\mathrm{ppb}$ ), and all were below the NIOSH REL for 2,3-pentanedione (range: $1.3 \mathrm{ppb}-3.6 \mathrm{ppb}$ ).

An area sample in the packaging area had the highest air concentrations of diacetyl $(10.2$ $\mathrm{ppb}$ ) and 2.3-pentanedione (5.6 ppb). Concentrations of the area air samples throughout the production room ranged from $4.8 \mathrm{ppb}-10.2 \mathrm{ppb}$ for diacetyl and from $2.7 \mathrm{ppb}-5.6 \mathrm{ppb}$ for 2,3-pentanedione. We note NIOSH RELs are intended to be directly compared with personal full-shift measurements; therefore, an area air sample exceeding a NIOSH REL is only an indication of potential personal exposures.

Only one personal air sample in the production area returned a result above LOD for 2,3-hexanedione (0.7 ppb). All area samples were below the LOD for 2,3-hexanedione.

\section{Task-based Air Sampling Results}

Facility A: We collected 14 personal task-based air samples, one seven minute sample and 13 with a duration of 14 minutes to 15 minutes, using OSHA Methods 1013/1016, (Table A3). An employee that ground roasted beans had the highest exposure to diacetyl $(60.2$ $\mathrm{ppb}$ ) and 2,3-pentanedione (41.4 ppb). An employee that moved roasted beans and ground coffee had the second highest exposure to diacetyl (52.4 ppb) and 2,3-pentanedione (32.5 $\mathrm{ppb}$ ). Grinding and moving roasted beans or ground coffee tasks also returned the highest measured 2,3-hexanedione concentrations, $2.9 \mathrm{ppb}$ and $2.0 \mathrm{ppb}$ respectively.

Seven of the 14 task-based samples had a duration of 15-minutes, allowing for comparison to the NIOSH STELs for diacetyl (25 ppb) and 2,3-pentanedione (31 ppb). Four of the seven samples exceeded the NIOSH STEL for diacetyl, and one exceeded the NIOSH STEL for 2,3-pentanedione. Two 15-minute samples taken while employees were roasting coffee and one sample taken while moving roasted beans or ground coffee exceeded the NIOSH STEL for diacetyl. One 15-minute sample taken while an employee was grinding coffee exceeded the NIOSH STELs for both diacetyl and 2,3-pentanedione.

Facility B: We collected nine personal task-based air samples using OSHA Methods 1013/1016 with durations ranging from 10 minutes to 15 minutes, (Table A4). An employee that ground roasted beans had the highest diacetyl (17.9 ppb) and 2,3-pentanedione (10.4 ppb) levels. Packaging coffee had the second highest concentrations of diacetyl (11.8 ppb diacetyl) and 2,3-pentanedione (7.4 ppb). An employee that roasted coffee beans had the third highest concentrations (9.2 ppb diacetyl; $5.5 \mathrm{ppb} 2,3$-pentanedione). Three of the nine taskbased samples had a duration of 15-minutes allowing for comparison to the NIOSH STELs. None of the three exceeded the STELs for diacetyl or 2,3-pentanedione.

Table A5 presents results for the three evacuated canister personal task-based air samples. All evacuated canisters were equipped with an instantaneous flow controller with a sample duration of approximately 30 seconds. Because of the short duration of these samples, results should not be compared with the 15-minute STELs. The sample taken while grinding 
roasted beans had the highest measured diacetyl concentration (19.3 ppb) and lowest 2,3-pentanedione concentration of $11.5 \mathrm{ppb}$. We collected one sample as an employee poured cooled roasted beans into a bin with a diacetyl concentration of $15 \mathrm{ppb}$ and a 2,3-pentanedione concentration of $11.8 \mathrm{ppb}$. We sampled an employee pouring roasted beans in the final bag for shipping that showed a diacetyl concentration of $15.7 \mathrm{ppb}$ and the highest 2,3-pentanedione concentration of $14.7 \mathrm{ppb}$. 2,3-Hexanedione concentrations for all three instantaneous task samples were at or below $1.0 \mathrm{ppb}$.

\section{Source Air Sampling Results}

Facility A: Table A6 presents results for the 19 evacuated canister source air samples. All evacuated canisters were equipped with an instantaneous flow controller with a sample duration of approximately 30 seconds. The highest concentrations were measured in four samples at a grinder while regular coffee (versus decaffeinated) was being ground, with diacetyl concentrations ranging from 6,393 ppb to 8,626 ppb, 2,3-pentanedione concentrations ranging from $4,763 \mathrm{ppb}$ to $5,899 \mathrm{ppb}$, and 2,3-hexanedione concentrations ranging from $212 \mathrm{ppb}$ to $261 \mathrm{ppb}$. We collected two source samples while freshly ground coffee was being transferred from one bag to another that had the next highest concentrations of diacetyl (1,072 ppb and 5,973 ppb), 2,3-pentanedione (535 ppb and 4,821 ppb), and 2,3-hexanedione (31.4 ppb and $253 \mathrm{ppb})$.

Facility B: Table A7 presents results for the 13 evacuated canister source air samples. All evacuated canisters were equipped with an instantaneous flow controller with a sample duration of approximately 30 seconds. The highest concentrations were measured in a sample at the grinder while decaffeinated coffee was being ground, with diacetyl concentration of 14,576 ppb, 2,3-pentanedione concentration of 7,281 ppb, and 2,3-hexanedione concentration of $464 \mathrm{ppb}$. Two source samples collected as roasted bean storage bins containing decaffeinated coffee were being opened had the next highest concentrations of diacetyl (1,085 ppb and 1,184 ppb), 2,3-pentanedione (409 ppb and $419 \mathrm{ppb}$ ), and 2,3-hexanedione (33.8 ppb and $40.6 \mathrm{ppb}$ ).

\section{Bulk Samples and Headspace Results}

Table A8 presents results of headspace analyses of the bulk samples collected at both facilities. The highest air concentrations of diacetyl (8,902 ppb and 6,504 ppb) and 2,3-pentanedione $(4,994 \mathrm{ppb}$ and 4,443 ppb) were associated with decaffeinated roasted coffee beans. 2,3-Hexanedione concentrations were generally below the LODs (four of seven samples) and lower than 2,3-pentanedione when measurable.

Real-time Monitoring: Carbon Dioxide (CO $\mathrm{C}_{2}$, and Carbon Monoxide (CO) and Total Volatile Organic Compounds (TVOCs)

\section{$\mathrm{CO}_{2}$ and $\mathrm{CO}$}

Facility A: Real-time monitoring with an averaging time of 10 seconds at the roaster showed $\mathrm{CO}_{2}$ levels ranging from 436 parts per million (ppm) - $706 \mathrm{ppm}$, and $\mathrm{CO}$ levels ranging from $0.7 \mathrm{ppm}-14.8 \mathrm{ppm}$. The highest peak of CO $(14.8 \mathrm{ppm})$ occurred when roasted coffee was being ground in the adjacent room. $\mathrm{CO}_{2}$ and $\mathrm{CO}$ levels observed at the roasted bean storage 
bins ranged from $650 \mathrm{ppm}-1,077 \mathrm{ppm}$, and from $0 \mathrm{ppm}-48.5 \mathrm{ppm}$ respectively. That peak (48.5 ppm) in CO occurred when a storage bin was opened adjacent to the sampling instrument. Also, when coffee grinding was occurring in the afternoon, the concentrations of both $\mathrm{CO}_{2}$ and $\mathrm{CO}$ were elevated throughout the production area. Sampling at the grinders for both days showed $\mathrm{CO}_{2}$ levels ranging from $472 \mathrm{ppm}-1,085 \mathrm{ppm}$, and $\mathrm{CO}$ levels ranging from $0 \mathrm{ppm}-119.8 \mathrm{ppm}$. Both $\mathrm{CO}_{2}$ and $\mathrm{CO}$ levels were at their highest when roasted coffee beans were ground with peak readings of 1085 ppm and 119.8 ppm respectively.

Facility B: Real-time monitoring with an averaging time of 10 seconds for $\mathrm{CO}_{2}$ and $\mathrm{CO}$ at the roaster showed $\mathrm{CO}_{2}$ levels ranging from $484 \mathrm{ppm}-1,041 \mathrm{ppm}$ and $\mathrm{CO}$ levels ranging from $0.6 \mathrm{ppm}-17.2 \mathrm{ppm}$. The highest observed CO concentrations in this area (17.2 ppm) occurred when roasted coffee beans were ground on the opposite side of the production area. $\mathrm{CO}_{2}$ and $\mathrm{CO}$ levels at the production area grinder ranged from $509 \mathrm{ppm}-968 \mathrm{ppm}$ and from $0.0 \mathrm{ppm}-142.7 \mathrm{ppm}$ respectively. The highest concentrations of CO (142.7 ppm) occurred when roasted coffee beans were ground. Real-time monitoring at the breakroom grinder showed levels ranging from $504 \mathrm{ppm}-1,243 \mathrm{ppm} \mathrm{CO}_{2}$, and $0.0 \mathrm{ppm}-9.6 \mathrm{ppm} \mathrm{CO}$. Again, the highest concentrations of $\mathrm{CO}$ were observed when roasted coffee beans were ground.

\section{TVOCs}

Facility A: Real-time monitoring of TVOCs at the roaster showed peak concentrations of 3,437 ppb as beans were dispensed from the roaster cooling bin near the instrument. TVOC real-time monitoring at the grinders showed higher concentrations, (peaks as high as 29,020 ppb), corresponding with when roasted coffee beans were ground. TVOC realtime monitoring at the roasted bean storage bins showed peak concentrations of 5,226 ppb corresponding with when the roasted bean storage bins were opened.

Facility B: The real-time TVOC monitoring results at the roaster showed a peak of 1,276 ppb when a batch of roasted beans was emptied into the cooling bin. The TVOC real-time monitoring device at the production area grinders showed higher concentrations were measured when roasted coffee beans were ground with observed peaks as high as 5,212 ppb.

\section{Ventilation Assessment}

Facility A: There was adequate air flow to/from all occupied areas on the office side of the facility to maintain temperature. The production area was neutral compared to the office area, meaning no migration of air from the production area into the office area was occurring at the time measurements were taken. The roasting room was neutral compared to the packaging/ grinding area and had open window fans suppling outdoor air producing a cross-draft air flow pattern from the green bean storage side to the roaster side of the room. Even when the roaster cooling bin was operating the pressures remained neutral. The packaging/grinding area was neutral compared to the adjacent storage area, meaning there was no migration of air from one area to the other. Window air-conditioning units were mounted in the walls of the roasting and production rooms to supply conditioned air, and multiple fans circulated air in various directions in the entire production area causing any contaminants generated in one area to be circulated throughout the rooms. 
The air conditioning units were well maintained; however, we did notice a musty odor in the office area, and upon further inspection, visible signs of water damage on the ceiling were observed. There were rusty holes in the outer shell of the building and water-damaged materials in the storage area above the office area.

Facility B: There was insufficient total air flow to/from all occupied areas on the office area side of the facility to maintain temperature control. Differential pressure measurements showed that the production space was under positive pressure in relationship to the administrative side of the facility. The pressure reading across the doorway between the production space and the office side of the facility was +0.007 inches of water. These conditions allow possible migration of contaminants into the nonproduction area. When the air conditioning and the roaster cooling bin were operating the pressure differential increased. This was likely due to minimal air-flow into the administration area.

A visual inspection of the central cooling unit and supply ducts showed that all systems were operating properly and the dust collector filters were changed on schedule. However, the system supplied minimal conditioned air to the office area and should be balanced by a certified technician to rectify this issue (see recommendations).

\section{Medical Surveys}

The medical survey results at both facilities were combined because of the small number of participants and the need to protect individual privacy. We do not provide more detailed results that would shed light on possible work-relatedness, such as health measures by job title or task.

\section{Demographics}

Eleven $(100 \%)$ onsite employees participated in the medical surveys. The majority of participants were male (64\%) and Caucasian (82\%), with a mean age of 41 years (range: 25-62 years) and average tenure at the respective coffee production facility of four years (range: 7 months -8 years). None reported working at any other coffee plant or other company that used flavorings. Six (55\%) participants were current or former smokers.

Ten $(91 \%)$ employees spent time in the production area of the coffee facilities, ranging from one to 40 hours per week. At least six (55\%) employees performed the following tasks: work with green beans, work where finished goods are stored, roast coffee beans, grind coffee beans, package coffee, and/or perform quality control activities.

\section{Symptoms and Self-Reported Diagnoses}

Reported symptoms are listed in Table A9 and were similar at both facilities. Nose symptoms were the most commonly reported symptom $(n=8,73 \%)$, followed by eye symptoms $(n=5$, $45 \%$ ). Some participants with nose and eye symptoms reported green coffee beans, burlap bags, grinding coffee, and dust as aggravations causing these symptoms at work. Breathing trouble $(n=4 ; 36 \%)$ followed by shortness of breath $(n=3 ; 27 \%)$ were among the most commonly reported lower respiratory symptom at both facilities. Grinding roasted coffee or being near roasted coffee storage bins at work was reported as aggravating lower respiratory 
symptoms. Two (18\%) of eleven participants reported physician-diagnosed asthma; both reported that their asthma developed before they began working at the coffee production facilities.

\section{Medical Tests}

One $(10 \%)$ of ten spirometry tests was interpreted as having an obstructive pattern with significant improvement after bronchodilator. Two (18\%) of eleven oscillometry tests were interpreted as consistent with large airway abnormality, and one (9\%) oscillometry test was interpreted as consistent with a small airway abnormality. One (9\%) of eleven exhaled nitric oxide test was interpreted as elevated.

\section{NHANES Comparison of Symptoms and Diagnoses}

The SMR for current physician-diagnosed asthma was elevated at 4.1 (Table A10). However, it is important to note that all cases were diagnosed before starting work at the facility and the expected number of participants with physician-diagnosed asthma was less than one, reflecting the small number of participants. SMRs for shortness of breath, wheeze, sinus problems, and nose and eye symptoms were not elevated in comparison to the general U.S. population, adjusted for age distribution, race/ethnicity, sex, and smoking history.

\section{Discussion}

Diacetyl, 2,3-pentanedione, 2,3-hexanedione, other VOCs, and other chemicals such as CO and $\mathrm{CO}_{2}$ are naturally produced when coffee beans are roasted, and grinding the roasted coffee beans produces greater surface area for the off-gassing of these chemicals [Anderson et al. 2003; Akiyama et al. 2003; Daglia et al. 2007; Newton 2002; Nishimura et al. 2003; Raffel and Thompson 2013]. Occupational exposure to diacetyl and 2,3-pentanedione can cause loss of lung function and the lung disease obliterative bronchiolitis [NIOSH 2016]. Industrial Hygiene Survey

\section{Alpha-Diketones}

\section{Personal Full-shift Air Sampling}

Overall, almost half of the full-shift personal sample concentrations for diacetyl were above the NIOSH REL and two samples exceeded the REL for 2,3-pentanedione. People who package/ground coffee had the highest exposures to alpha-diketones (e.g., diacetyl, 2,3-pentanedione). Office area employees spending time in the production area while these tasks were occurring also had the potential for exposure.

Facility A: All four personal full-shift air samples taken in the packaging room (Table A1) were above the NIOSH REL for diacetyl, and two of those also exceeded the NIOSH REL for 2,3-pentanedione. The more often grinding/packaging tasks are performed, the higher full-shift air concentrations for the alpha-diketones can be elevated; this was the case at another coffee roasting and packaging facility NIOSH evaluated [Duling et al. 2016]. During task-based air sampling (Table A3), an employee that ground roasted beans for 15-minutes 
had the highest diacetyl (60.2 ppb) and the highest 2,3-pentanedione (41.4 ppb) levels indicating that those tasks likely contributed to the elevated sample concentrations in that area.

The REL should be used as a guideline to indicate when steps should be taken to reduce exposures in the workplace. The risks associated with the measured levels are higher than NIOSH recommends. As described in the quantitative risk assessment from the NIOSH Criteria Document (Table 5-27) [NIOSH 2016], after a 45-year working lifetime exposure to $20 \mathrm{ppb}$ (a concentration higher than the highest concentration of $17.6 \mathrm{ppb}$ measured at this facility), NIOSH estimated 3 in 1,000 workers would develop reduced lung function (FEV1 below the 5 th percentile). NIOSH predicted that around 5 in 10,000 workers exposed to diacetyl at $20 \mathrm{ppb}$ would develop more severe lung function reduction (FEV1 below $60 \%$ predicted, defined as at least moderately severe by the American Thoracic Society [Pellegrino et al. 2005]). The effects of a working lifetime exposure at $17.6 \mathrm{ppb}$ would be somewhat less than those for $20 \mathrm{ppb}$. NIOSH recommends keeping diacetyl concentrations below $5 \mathrm{ppb}$ because at this level, the risk of reduced lung function after a working lifetime of exposure is below 1 in 1000 workers. NIOSH recommends taking steps to reduce diacetyl exposures to below the REL of 5 ppb whenever possible.

Facility B: Six of nine personal full-shift air samples (Table A2) were above the NIOSH REL for diacetyl; however, none exceeded the NIOSH REL for 2,3-pentanedione. Two of the three personal samples in the office area were above the REL for diacetyl showing that contaminants from the production area were migrating into the office area. During task-based air sampling (Table A4), an employee that ground roasted beans for 13-minutes had the highest diacetyl (17.9 ppb) and the highest 2,3-pentanedione (10.4 ppb) levels indicating that those tasks likely contributed to the elevated sample concentrations in that area.

According to the quantitative risk assessment from the NIOSH Criteria Document (Table 5-27) [NIOSH 2016], after a 45-year working lifetime exposure to $10 \mathrm{ppb}$ (a concentration higher than the highest concentration measured at this facility), NIOSH estimated 2 in 1,000 workers would develop reduced lung function (FEV1 below the 5th percentile). NIOSH predicted that around 2 in 10,000 workers exposed to diacetyl at 10 ppb would develop more severe lung function reduction (FEV1 below $60 \%$ predicted, defined as at least moderately severe by the American Thoracic Society [Pellegrino et al. 2005]). The effects of a working lifetime exposure at $9.4 \mathrm{ppb}$ would be somewhat less than those for $10 \mathrm{ppb}$. NIOSH recommends keeping diacetyl concentrations below 5 ppb because at this level, the risk of reduced lung function after a working lifetime of exposure is below 1 in 1000 workers. NIOSH recommends taking steps to reduce diacetyl exposures to below the REL of $5 \mathrm{ppb}$ whenever possible.

\section{Both Facilities}

At both facilities, only one of four total personal samples collected during roasting (Tables A1 and A2) were above the NIOSH RELs for diacetyl, and none were above the NIOSH REL for 2,3-pentanedione. At facilities A and B, the roaster operators often remained at or near the roaster control panels during the roasting process. Each roasting drum was fully enclosed, 
and air was exhausted outdoors through the wall or roof, minimizing exposures indoors. The only time the roasting drum was opened was during the transfer of roasted beans into the cooling drum. The downdraft system on the roaster machines pulled air over the roasted beans and down into the cooling drum to accelerate cooling which likely decreased the roaster operator's exposure.

\section{Area Full-shift Air Sampling}

About half of the area samples collected at facility A where coffee was packaged and ground (Table A1) exceeded the NIOSH REL for diacetyl. However, at facility B almost all area samples taken in the production room and office area (grinding, packaging, roasting, and office area, Table A2) exceeded the NIOSH REL for diacetyl. This is most likely due to the openness of the production area and its positive pressure in relation to the administration area. Also, in facility B, the door between the administration area and production area was frequently left open to aid in the cooling of the administration area. This orientation is unfavorable due to the migration of alpha-diketones generated in the production area into the administration area. As noted earlier, NIOSH RELs and STELs are intended to be directly compared to personal TWA measurements; therefore, an area air sample that exceeds a NIOSH REL is only an indication of potential for personal exposures.

\section{Instantaneous Air Sampling}

Throughout the shift, roaster operators emptied buckets of freshly roasted coffee beans into roasted coffee bean storage bins. The roasted coffee beans off-gassed in these bins. Using evacuated canisters, we measured high instantaneous concentrations of diacetyl (19.5 ppb - 1,085 ppb) and 2,3-pentanedione (7.4 ppb - $419 \mathrm{ppb})$ inside roasted bean storage bins. A sample taken in the breathing zone while an employee ground coffee showed $19.3 \mathrm{ppb}$ diacetyl and 11.5 ppb 2,3-pentanedione (Table A5), which could represent the potential exposures encountered during 30 seconds of grinding coffee.

\section{Task-Based Exposures}

Coffee processing involves multiple tasks that may cause intermittent exposure to diacetyl and 2,3-pentanedione. Traditional full-shift sampling will not characterize these intermittent, peak exposures. Evaluating intermittent and task-based exposures to diacetyl and 2,3-pentanedione is difficult with current validated sampling methods (OSHA Methods 1013/1016). Since tasks are so sporadic in coffee processing, with some only lasting a few seconds or minutes, we used instantaneous evacuated canisters to sample tasks that were only a few seconds to minutes long and OSHA Methods 1013/1016 for longer duration tasks. We sampled by task, with varying durations, to understand which tasks may have contributed to higher exposures to diacetyl and 2,3-pentanedione.

Our task-based air sampling revealed that some tasks had higher air concentrations of diacetyl and/or 2,3-pentanedione than other tasks. As noted earlier, a 15-minute personal air sample taken at facility A during grinding roasted coffee exceeded the STELs for diacetyl and 2,3-pentanedione with results of $60.2 \mathrm{ppb}$ and $41.4 \mathrm{ppb}$ respectively. This sample concentration exceeded the NIOSH STEL of $25 \mathrm{ppb}$ for diacetyl and $31 \mathrm{ppb}$ for

2,3-pentanedione. Another 13-minute personal task sample taken at facility B during 
grinding roasted coffee (17.9 ppb, diacetyl; $10.4 \mathrm{ppb}, 2,3$-pentanedione) did not exceed the STELs assuming zero concentration for the remaining two minutes of the sample. Using instantaneous ( 30 seconds) evacuated canisters taken at the source, not in the breathing zone, we also observed in both facilities that grinding roasted coffee resulted in the highest diacetyl (range: 1,124 - 14,576 ppb) and 2,3-pentanedione (range: $768 \mathrm{ppb}-7,281 \mathrm{ppb)} \mathrm{air}$ concentrations (Tables A6, A7). These samples were taken directly at the grinder discharge for a short period of time and cannot be compared to the STELs. The greater surface area for off-gassing that is produced during grinding can result in the higher air concentrations of those chemicals during that task [Akiyama et al. 2003]. Amount, frequency and the number of grinders running simultaneously were not accounted for in these task samples, only the number of minutes sampled while grinding, which could produce significant variability in the task results.

At facility A, samples taken while moving roasted beans or ground coffee tasks showed elevated levels of diacetyl and 2,3-pentanedione. Using OSHA Methods 1013/1016, those tasks resulted in elevated diacetyl (range: $38.3-52.4 \mathrm{ppb}$ ) and 2,3-pentanedione (range: $24.0-34.5 \mathrm{ppb}$ ) air concentrations (Table A3). Opening roasted bean storage bins and hand scooping whole bean or ground coffee are tasks at both facilities that require the offgassing product to be in close proximity to the worker's breathing zone resulting in high sample concentrations. As part of packaging coffee tasks, employees at both facilities often had to weigh and pack different blends of roasted beans. In order to blend different roasted beans together, an employee weighed out the proper amount of each roast type and blended the beans together in plastic buckets by hand with a scoop. Employees placing their heads above the plastic storage bin or bucket while hand blending the roasted beans would likely contribute to higher measured alpha-diketones. Using OSHA Methods 1013/1016, packaging coffee tasks at both facilities resulted in elevated diacetyl (range: $3.7 \mathrm{ppb}-33.4 \mathrm{ppb}$ ) and 2,3-pentanedione (range: $1.1 \mathrm{ppb}-19.6 \mathrm{ppb}$ ) air concentrations (Tables A3 and A4). At both facilities using instantaneous evacuated canisters taken at the source not in the breathing zone, (Tables A6 and A7), we also observed that blending by hand and transferring roasted or ground coffee resulted in elevated diacetyl (range: $29.5-5,973 \mathrm{ppb}$ ) and 2,3-pentanedione $(13.9-4,821 \mathrm{ppb})$ air concentrations.

\section{Bulk Samples}

Diacetyl is not found in green beans. Rather, diacetyl is generated later in the coffee roasting process [Daglia et al. 2007]. We do not know how long the beans were in the storage bins prior to collecting the samples, but generally the time between roasting and packaging is on the order of hours to days. The amount of time roasted beans had off-gassed could be responsible for differences in headspace analysis results. As shown in Table A8, the concentrations of diacetyl and 2,3-pentanedione in decaffeinated coffee were significantly higher than the other samples. While there weren't enough samples taken to effectively determine a greater potential for alpha-diketone concentrations emitted from decaffeinated coffee, the higher levels should be noted and extra care used when opening storage bins and grinding decaffeinated coffee beans. 
Carbon Monoxide, Carbon Dioxide and TVOCs

We observed high levels of $\mathrm{CO}, \mathrm{CO}_{2}$ and TVOCs when opening roasted bean storage bins. Although those levels were very high inside the roasted bean storage bins, and elevated during grinding tasks the levels were generally low throughout the other areas of the facilities. However, elevated concentrations of $\mathrm{CO}, \mathrm{CO}_{2}$ and TVOCs were observed in adjacent areas of the facilities when the grinding of coffee beans was occurring. The offgassing and grinding of roasted coffee beans produces those highest concentrations observed. As a precaution, employees should not place their heads or faces inside the roasted bean storage bins, directly outside uncovered bins or near the discharge or vent of the grinder.

\section{Ventilation}

We did not have the equipment to accurately determine the amount of fresh, outdoor air being supplied at either facility, but our calculations show that as little as 10 percent outdoor air would meet the outdoor air requirements set forth in American National Standards Institute (ANSI)/ASHRAE Standard 62.1: Ventilation for Acceptable Indoor Air Quality for typical occupancy levels [ANSI/ASHRAE 2016]. During periods of high occupancy in the break rooms and/or conference rooms, as much as 20 percent outdoor air may be necessary.

Facility A: The ventilation systems serving the facility provided adequate total air flow to maintain temperature control. The production area would benefit from the installation of local exhaust to vent the grinder emissions outdoors. This is shown by the elevated full-shift air sample concentrations of alpha-diketones in the production area and the task samples taken while grinding.

Facility B: The pressure differential measurements showed the undesirable condition of production area air migrating into the administration area. During our visit, the door between the two areas remained open to aid in cooling of the administration area. The personal sampling results in the administration area confirmed those findings. Three of the four personal samples in that area exceeded the NIOSH REL for diacetyl. Inspection of the air handling unit also showed minimal airflow into the administration area. The bulk of the air was vented into the production area through four large vents in the wall separating the two areas. More conditioned air flow is needed into the administration area to maintain optimal temperature control. Also, exhausting more air out of the production area would create the more favorable neutral or positive pressure in the administration area. Installing local exhaust ventilation to vent grinder emissions outdoors could help to remove contaminants and reduce air pressure in the production area relative to the administration area.

\section{Indoor Dampness \\ Facility A}

Evidence of water incursion was observed in the office area. Research has found that damp building conditions can lead to respiratory illnesses in occupants. Dampness in buildings can occur for a variety of reasons such as high indoor humidity, condensation, and roof leaks. Damp building conditions promote the growth of mold, bacteria, and other microbial agents, as well as dust mites and cockroaches. Dampness can also contribute to the breakdown of building materials and furniture. Musty odors are a sign of microbial 
contamination. Building occupants in damp buildings can be exposed to pollutants in the air from biological contaminants and the breakdown of building materials. Implementing periodic room inspections for dampness can help to identify trouble areas before they become major problems. For example, conducting observational inspections in buildings quarterly provides documentation of dry versus damp areas, and help to prioritize maintenance and repair. Wetted materials need to be dried within 48 hours of getting wet or subsequently removed, and necessary repairs need to be made to prevent further water entry into the building. If mold is identified on materials, appropriate remediation guidelines with proper containment are recommended to minimize exposure to building occupants. The document developed by the New York City Department of Health and Mental Hygiene (NYCDH\&MH), Guidelines on Assessment and Remediation of Fungi in Indoor Environments, provides guidance for cleaning mold-damaged materials [NYCDH\&MH 2008].

\section{Medical Survey}

Nose and eye symptoms were the most commonly reported symptoms at both facilities. Some employees reported their nose and eye symptoms were caused or aggravated by green coffee beans, burlap bags, grinding coffee, or dust. Green and roasted coffee dust and castor beans (from cross-contamination of bags used to transport coffee) are known risk factors for occupational asthma [Figley and Rawling 1950; Karr et al. 1978; Zuskin et al. 1979, 1985; Thomas et al. 1991]. Persons who become sensitized (develop an immune reaction) to coffee dust can subsequently react to relatively low concentrations in the air. Others may experience irritant-type symptoms from exposure to coffee dust [Oldenburg et al. 2009].

Upper respiratory disease such as allergic rhinitis (hay fever, nasal allergies) and sinusitis are sometimes associated with lower respiratory symptoms and asthma, and may precede the diagnosis of asthma [Shaaban et al. 2008; EAACI Task Force on Occupational Rhinitis et al. 2008; Rondón et al. 2012, 2017; Sahay et al. 2016]. Upper respiratory involvement (e.g., rhinitis, sinusitis) can result in suboptimal control of asthma. Some participants that reported lower respiratory symptoms also reported nasal or sinus problems, but none reported their upper respiratory symptoms to be work-related.

Green coffee dust is thought to be a more potent allergen than roasted coffee dust because roasting destroys some of the allergenic activity [Lehrer et al. 1978]. As discussed in the recommendations section, to prevent symptoms related to green coffee dust and chaff, make N-95 disposable filtering-face piece respirators available for voluntary use when emptying burlap bags of green beans into the storage silos or when emptying the chaff containers or cleaning the green bean storage area.

Two participants reported current asthma; however, both participants reported asthma diagnoses before hire at the coffee production facility. Exposure to certain workplace triggers, which could include green coffee dust, has the potential to exacerbate symptoms in some people with asthma. Asthma symptoms often improve when away from exposures that trigger symptoms while other lung diseases such as obliterative bronchiolitis symptoms or chronic obstructive pulmonary disease (COPD) generally do not improve. Spirometry 
can be used to help detect and follow individuals with asthma and other lung diseases such as obliterative bronchiolitis or COPD. Spirometry can show if air is exhaled from the lungs more slowly than normal (i.e. obstructive abnormality) or if the amount of air exhaled is smaller than normal (i.e., restrictive abnormality). In asthma, there is intermittent airways obstruction which is reversible after treatment with bronchodilator medications (e.g., albuterol). In obliterative bronchiolitis, scar tissue prevents the small airways (bronchioles) from opening up when albuterol is given. In other words, the airways are fixed and not responsive (reversible) to bronchodilator medicine. The obstructed airways prevent rapid emptying of the lung air sacs (alveoli) during exhalation. This explains why the respiratory symptoms of those with occupational obliterative bronchiolitis do not tend to improve when away from work-related exposures; however, avoidance of further exposure can stop progression of the disease [Akpinar-Elci et al. 2004].

Spirometry and impulse oscillometry measure different things. Spirometry assesses airflow and is the breathing test typically used to screen for flavoring-related lung disease. Impulse oscillometry accesses the airways response to a sound or pressure wave and has not commonly been used to screen for flavoring-related lung disease. In general, during the impulse oscillometry test, a small pressure impulse (sound wave) is imposed upon the inspiratory and expiratory airflow during normal tidal breathing. This pressure wave causes a disturbance in the airflow and pressure, and the response of the airways (i.e., change in pressure to change in flow) is a measure of the resistance to airflow in the airways [Desiraju and Agrawal 2016]. Impulse oscillometry may be useful as an indirect measure of airflow obstruction and helpful in individuals not able to perform forced breathing maneuvers that are required during the spirometry test. The impulse oscillometry test has been used for many years to measure changes in the airways of children with lung problems such as asthma and cystic fibrosis [Song et al. 2008; Komarow et al. 2011; Shi et al. 2012; Schulze et al. 2016]. More recently, impulse oscillometry has been used to investigate lung problems in adults exposed to dust or chemicals, such as World Trade Center emergency responders and soldiers returning from deployment overseas [Oppenheimer et al. 2007; Berger et al. 2013; Weinstein et al. 2016]. Over the years, researchers have developed reference (predictive) equations for different populations of children for oscillometry [Malmberg et al. 2002; Park et al. 2011; Lee et al. 2012; de Assumpção et al. 2016]. For adults, there are fewer reference equations available for oscillometry [Vogel and Smidt 1994; Newbury et al. 2008; Schulz et al. 2013]. The predicted values we used for oscillometry measures were based on gender and age according to references values recommended by the manufacturer. Unlike predictive equations used for spirometry, the impulse oscillometry reference equations we used did not take into account height, race, or smoking status [Vogel and Smidt 1994].

Our findings of lower respiratory symptoms and nose and eye symptoms in some employees and abnormal breathing tests suggest respiratory problems in this workforce. The nose and eye symptoms that are work-related (improve away from work or aggravated by something at work) are likely related to workplace exposures. However, breathing trouble, shortness of breath, and other lower respiratory symptoms reported at both facilities did not show workrelated patterns to the same extent. These lower respiratory symptoms and the lung function abnormalities we found are not specific to a particular respiratory problem or disease. They 
could be related to workplace exposures or to other factors. Indeed, some employees had asthma diagnoses that preceded employment at this facility. Because of the small number of participants and the need to protect individuals' privacy, we do not provide more detailed results, such as health measures by job title or task.

We recommend starting a medical monitoring program because air sampling detected employee exposures to diacetyl and 2,3-pentanedione that exceeded the NIOSH RELs, and there were some participants with abnormal breathing tests or history of lower respiratory symptoms. All production employees and any employees that assist with production tasks (e.g., roasting, interacting with open storage bins/containers of roasted coffee, grinding, weighing, or packaging coffee) should participate in the workplace medical monitoring program. A medical monitoring program is a means of early identification of employees who may be developing lung disease (e.g., asthma, obliterative bronchiolitis) and can help prioritize interventions to prevent occupational lung disease. The NIOSH medical survey results can serve as a baseline for employees who participated, if they choose to share these results with the provider. In a workplace with risk of occupational lung disease, prevention of smoking-related lung disease is important and makes the detection of work-related adverse effects easier. The Centers for Disease Control and Prevention offers tools and resources for setting up a smoking cessation program [CDC 2017].

\section{Conclusions}

We identified specific work tasks at both facilities that resulted in air concentrations of diacetyl that exceeded the NIOSH REL and STEL. Grinding roasted coffee beans, blending roasted coffee beans by hand, and weighing and packaging roasted coffee were associated with higher diacetyl levels, likely due to the close proximity of the employee's breathing zone to the roasted beans. $\mathrm{CO}$ and $\mathrm{CO}_{2}$ levels were low throughout most of the facility, and the highest $\mathrm{CO}$ and $\mathrm{CO}_{2}$ levels were observed at the openings of roasted bean storage bins; however, this may not be representative of employee exposure.

Sample results in facility A indicate that the installation of local exhaust ventilation near the grinders in the production area could contribute to lower diacetyl and 2,3-pentanedione concentrations by removing contaminants at the source. Ventilation measurements in facility B supported sampling results which showed the air concentrations of alpha-diketones (e.g., diacetyl, 2,3-pentanedione, 2,3-hexanedione) were migrating into the administration area. Change ventilation system air flow distribution so that the administration area has a positive pressure relationship to the production area.

Overall, nose and eye symptoms were the most commonly reported symptoms at both facilities. Some employees reported their nose and eye symptoms were caused or aggravated by green coffee beans, burlap bags, grinding coffee, or dust. Breathing trouble and shortness of breath were among the most commonly reported lower respiratory symptoms at both facilities. One (10\%) of 10 spirometry tests were abnormal. One $(9 \%)$ of eleven participants had high exhaled nitric oxide, a marker of allergic airways inflammation. We recommend a 
medical monitoring program to identify any employees who may be developing lung disease (e.g., asthma, obliterative bronchiolitis) and to help management prioritize interventions to prevent occupational lung disease. All production workers and employees that assist with production tasks (e.g., roasting, interacting with open storage bins/containers of roasted coffee, grinding, weighing, or packaging coffee) should participate in the workplace medical monitoring program.

\section{Recommendations}

On the basis of our findings, we recommend the actions listed below. We encourage both coffee roasting and packaging facilities to use a labor-management health and safety committee or working group to discuss our recommendations and develop an action plan. Our recommendations are based on an approach known as the hierarchy of controls. This approach groups actions by their likely effectiveness in reducing or removing hazards. In most cases, the preferred approach is to eliminate hazardous materials or processes and install engineering controls to reduce exposure or shield employees.

\section{Engineering Controls}

Engineering controls reduce employees' exposures by removing the hazard from the process or by placing a barrier between the hazard and the employee. Engineering controls protect employees effectively without placing primary responsibility of implementation on the employee.

\section{Facility A}

1. Operate the window fan continuously during the work shift. Operating this equipment will help dilute and remove airborne alpha-diketones (e.g., diacetyl, 2,3-pentanedione, and 2,3-hexanedione) as they are generated and help maintain the production space under negative pressure relative to the administrative offices.

2. Consult with a ventilation engineer to design and install local exhaust ventilation at the grinders.

3. If other engineering and administrative controls (see below) do not reduce air concentrations of alpha-diketones, work with a ventilation engineer to install local exhaust ventilation during the following tasks:

i. blending roasted coffee by hand (if practice continues);

ii. grinding roasted coffee, and

iii. weighing and packaging roasted coffee.

4. Investigate and repair the source(s) of water incursion and remove water-damaged materials.

\section{Facility B}

Consult with a ventilation engineer to balance the HVAC system so that the administration area remains under positive pressure with respect to the production area. This will keep airborne alpha-diketones (e.g., diacetyl, 2,3-pentanedione, and 2,3-hexanedione) generated in 
the production area from migrating into the administration area.

1. Consult with a ventilation engineer to design and install local exhaust ventilation at the grinders.

2. If other engineering and administrative controls (see below) do not reduce air concentrations of alpha-diketones, work with a ventilation engineer to install local exhaust ventilation during the following tasks:

i. blending roasted coffee by hand (if practice continues);

ii. grinding roasted coffee, and

iii. weighing and packaging roasted coffee.

3. Install a closure on the door between the production and administration areas to ensure it remains closed at all time.

\section{Administrative Controls}

Administrative controls are employer-dictated work practices and policies implemented to reduce or prevent hazardous exposures. Their effectiveness depends on employer commitment and employee acceptance. Regular monitoring and reinforcement are necessary to ensure that policies and procedures are followed consistently.

1. Periodically clean the roasters' exhausts in accordance with manufacturer instructions to remove chaff build up to reduce a fire hazard and to improve the efficiency, energy usage, and roaster performance.

2. Include roaster exhaust checks and any future local exhaust systems in a preventive maintenance schedule to ensure they operate appropriately.

3. Continue to cover bins of roasted beans to reduce the overall emission of alphadiketones and other chemicals (e.g., $\mathrm{CO}, \mathrm{CO}_{2}$ ) into the workplace and lower worker exposure.

4. To reduce exposures to VOCs (including alpha-diketones), $\mathrm{CO}$, and $\mathrm{CO}_{2}$, minimize production tasks that require employees to place their heads inside or near the openings of the roasted bean storage bins.

5. Do not blend roasted beans by hand. Instead, use the agitator of the cooling drum or some other automatic mechanism to minimize employee contact with roasted beans during blending.

6. Conduct follow-up personal air sampling on employees with primary duties in the production area to verify that the modifications have been effective in reducing alphadiketone exposures to below the recommended exposure limits.

7. Always use a vacuum system with a high-efficiency particle air filter and wet methods for cleaning whenever possible.

8. Ensure employees understand potential hazards (e.g., diacetyl, 2,3-pentanedione, $\mathrm{CO}, \mathrm{CO}_{2}$, dust) in the workplace and how to protect themselves. OSHA's Hazard Communication Standard, also known as the "Right to Know Law" [29 CFR 
1910.1200] requires that employees are informed and trained on potential work hazards and associated safe practices, procedures, and protective measures.

9. Ensure employees are educated to consider the risks of further exposure if they develop lower respiratory symptoms (e.g., cough, shortness of breath, wheezing) that are progressive and severe in degree. Employees should report new, persistent, or worsening symptoms to their personal healthcare providers and to a designated individual at this workplace. Employees with new, persistent, or worsening symptoms should share this report with their healthcare providers.

\section{Personal Protective Equipment}

If follow-up air sampling, after engineering and administrative controls have been implemented, indicates levels of diacetyl and 2,3-pentanedione above their respective NIOSH RELs and STELs, we recommend that respiratory protection be used during tasks with elevated exposures. Personal protective equipment in the form of respiratory protection is considered the least effective means for controlling hazardous respiratory exposures because breakdowns in implementation can result in insufficient protection. Proper use of respiratory protection (respirators) requires a comprehensive respiratory protection program and a high level of employee and management involvement and commitment to assure that the right type of respirator is chosen for each hazard, respirators fit users and are maintained in good working order, and respirators are worn when they are needed. Supporting programs such as training, change-out schedules, and medical assessment may be necessary. Respirators should not be the sole method for controlling hazardous inhalation exposures. Rather, respirators should be used until effective engineering and administrative controls are in place.

1. In addition to engineering and administrative controls, respiratory protection is a potential option to further reduce exposures to alpha-diketones (e.g., diacetyl and 2,3-pentanedione). If follow-up air sampling, after engineering and administrative controls have been implemented, indicates levels of diacetyl and 2,3-pentanedione above their respective NIOSH RELs and STELs, we recommend that respiratory protection be used during tasks with elevated exposures. Respirators used to reduce exposures to diacetyl and 2,3-pentanedione should be NIOSH-certified and equipped with organic vapor cartridges. The choice of respirator should be guided by personal exposure sampling for diacetyl and 2,3-pentanedione [NIOSH 2004]. For reference, air-purifying half-face respirators have an assigned protection factor (APF) of 10 , and air-purifying full-face respirators have an APF of 50. Also, there are poweredair purifying respirators that have APFs of 25, 50, or 1000. A respirator's APF refers to the maximal level of protectiveness a specific respirator design can achieve under laboratory conditions. The OSHA APFs can be found in Table 1 of OSHA Respiratory Protection Standard at https:/www.osha.gov/pls/oshaweb/owadisp.show document?p table=STANDARDS\&p id=12716.

If mandatory respiratory protection is used, a written respiratory protection program should be implemented as required by the OSHA Respiratory Protection Standard (29 CFR 1910.134), including training, fit testing, maintenance, and use requirements. 
2. Offer employees the voluntary use of N95 disposable filtering facepiece respirators when emptying burlap bags of green beans into the storage silos, when cleaning the exhaust system of chaff, when emptying the chaff containers, or cleaning the green bean storage area. N95 respirators should be available in various sizes, and each potential N95 user should receive a copy of Appendix D of the OSHA Respiratory Protection Standard (http://www.osha.gov/pls/oshaweb/owadisp.show document?p

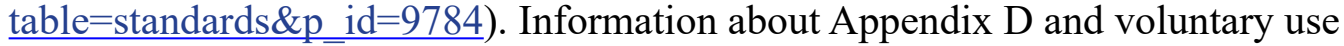
of respirators can be found on the OSHA website at https://www.osha.gov/video/ respiratory protection/voluntaryuse transcript.html.

Please be aware that N95s are not protective against alpha-diketones (diacetyl, 2,3-pentanedione, or 2,3-hexanedione). In cases of dual exposure to dust and alphadiketones, NIOSH-certified organic vapor cartridges (for the alpha-diketones) and particulate cartridges/filters (for the dust) would be warranted.

\section{Medical Monitoring}

The purpose of a medical monitoring program is to help assure the health of employees who have workplace exposures (e.g., diacetyl, 2,3-pentanedione, green coffee beans/dust) known to pose risk for potentially serious health conditions such as asthma or obliterative bronchiolitis.

1. Institute a medical monitoring program for employees who work or assist in the production area. The medical monitoring should consist of evaluation with a questionnaire (to obtain health and work task information) and spirometry (to assess lung function) at baseline and at one year to monitor for respiratory symptoms and to establish employees' baseline in lung function and any abnormal decline in lung function in the first year. Subsequently, an annual questionnaire evaluation should occur to monitor for respiratory symptoms. New or worsening respiratory symptoms should prompt additional evaluation including spirometry. Details about spirometry and a medical monitoring program can be found in chapter 9 of the NIOSH Criteria Document [NIOSH 2016].

2. If an employee is identified as likely having lung disease from exposure to diacetyl or 2,3-pentanedione, it should be viewed as a sentinel event indicating that there was a breakdown in exposure controls and that there is potential risk for co-workers. Should this occur, the unanticipated source of exposure must be identified and brought under control. In addition, increased intensity of medical surveillance would be required for all employees performing similar job tasks or having similar or greater potential for exposure. The NIOSH Criteria Document provides detailed guidance on responses to such sentinel events [NIOSH 2016].

\section{Smoking Cessation Program}

In a workplace with risk of occupational lung disease, prevention of smoking-related lung disease is important and makes the detection of work-related adverse effects easier. We recommend implementing a smoking cessation program to assist employees to stop smoking. 
The Centers for Disease Control and Prevention offers tools and resources for setting up a smoking cessation program [CDC 2017]. 


\section{Appendix A: Tables}

Table A1. OSHA Methods 1013/1016 full-shift personal and area air sampling results by location Facility A, NIOSH industrial hygiene survey, May 2016.

\begin{tabular}{|c|c|c|c|c|c|c|c|}
\hline Analyte & $\begin{array}{l}\text { Sample } \\
\text { Type }\end{array}$ & Location & $\mathbf{N}$ & $\begin{array}{c}\text { Above } \\
\text { LOD N } \\
(\%)\end{array}$ & $\begin{array}{c}\text { Minimum } \\
\text { Concentration } \\
\quad(p p b)\end{array}$ & $\begin{array}{c}\text { Maximum } \\
\text { Concentration } \\
\quad(p p b)\end{array}$ & $\begin{array}{l}\text { Above } \\
\text { REL N }\end{array}$ \\
\hline Diacetyl & Personal & Office Area & 6 & $4(67 \%)$ & $<0.3$ & 1.0 & 0 \\
\hline Diacetyl & Personal & Packaging & 4 & $4(100 \%)$ & 6.0 & 17.6 & 4 \\
\hline Diacetyl & Personal & Roasting & 2 & $2(100 \%)$ & 2.4 & 3.9 & 0 \\
\hline Diacetyl & Area & Café & 2 & $1(50 \%)$ & $<0.3$ & 1.0 & $\mathrm{~N} / \mathrm{A}$ \\
\hline Diacetyl & Area & Grinding & 2 & $2(100 \%)$ & 7.5 & 25.1 & N/A \\
\hline Diacetyl & Area & Office Area & 5 & $4(80 \%)$ & $<0.3$ & 0.8 & N/A \\
\hline Diacetyl & Area & Outside & 2 & $0(0 \%)$ & $<0.3$ & $<0.3$ & $\mathrm{~N} / \mathrm{A}$ \\
\hline Diacetyl & Area & Packaging & 1 & $1(100 \%)$ & 5.6 & 5.6 & N/A \\
\hline Diacetyl & Area & Weigh/Blend & 3 & $3(100 \%)$ & 2.2 & 17.3 & N/A \\
\hline Diacetyl & Area & Roasting & 2 & $2(100 \%)$ & 4.4 & 10.0 & $\mathrm{~N} / \mathrm{A}$ \\
\hline 2,3-Pentanedione & Personal & Office Area & 6 & $3(50 \%)$ & $<0.3$ & 0.7 & 0 \\
\hline 2,3-Pentanedione & Personal & Packaging & 4 & $4(100 \%)$ & 3.9 & 11.8 & 2 \\
\hline 2,3-Pentanedione & Personal & Roasting & 2 & $2(100 \%)$ & 1.3 & 2.4 & 0 \\
\hline 2,3-Pentanedione & Area & Café & 2 & $2(100 \%)$ & 0.3 & 0.7 & $\mathrm{~N} / \mathrm{A}$ \\
\hline 2,3-Pentanedione & Area & Grinding & 2 & $2(100 \%)$ & 4.7 & 15.5 & N/A \\
\hline 2,3-Pentanedione & Area & Office Area & 5 & $4(80 \%)$ & $<0.3$ & 0.6 & N/A \\
\hline 2,3-Pentanedione & Area & Outside & 2 & $0(0 \%)$ & $<0.3$ & $<0.3$ & N/A \\
\hline 2,3-Pentanedione & Area & Packaging & 1 & $1(100 \%)$ & 3.5 & 3.5 & N/A \\
\hline 2,3-Pentanedione & Area & Weigh/Blend & 3 & $3(100 \%)$ & 1.0 & 10.8 & N/A \\
\hline 2,3-Pentanedione & Area & Roasting & 2 & $2(100 \%)$ & 2.6 & 5.8 & $\mathrm{~N} / \mathrm{A}$ \\
\hline 2,3-Hexanedione & Personal & Office Area & 6 & $0(0 \%)$ & $<0.5$ & $<0.6$ & - \\
\hline 2,3-Hexanedione & Personal & Packaging & 4 & $3(75 \%)$ & $<0.5$ & 1.3 & - \\
\hline 2,3-Hexanedione & Personal & Roasting & 2 & $0(0 \%)$ & $<0.4$ & $<0.5$ & - \\
\hline 2,3-Hexanedione & Area & Café & 2 & $0(0 \%)$ & $<0.5$ & $<0.5$ & $\mathrm{~N} / \mathrm{A}$ \\
\hline 2,3-Hexanedione & Area & Grinding & 2 & $2(100 \%)$ & 0.6 & 1.1 & N/A \\
\hline 2,3-Hexanedione & Area & Office Area & 5 & $0(0 \%)$ & $<0.5$ & $<0.5$ & N/A \\
\hline 2,3-Hexanedione & Area & Outside & 2 & $0(0 \%)$ & $<0.4$ & $<0.5$ & N/A \\
\hline 2,3-Hexanedione & Area & Packaging & 1 & $1(100 \%)$ & 0.5 & 0.5 & N/A \\
\hline 2,3-Hexanedione & Area & Weigh/Blend & 3 & $1(33 \%)$ & $<0.5$ & 0.8 & $\mathrm{~N} / \mathrm{A}$ \\
\hline 2,3-Hexanedione & Area & Roasting & 2 & $1(50 \%)$ & $<0.4$ & 0.6 & N/A \\
\hline
\end{tabular}

Note: OSHA=Occupational Safety and Health Administration; NIOSH=National Institute for

Occupational Safety and Health; $N=$ number of samples; Above LOD N $(\%)=$ number and percentage of samples above limit of detection (LOD); < indicates below the limit of detection; Above REL N=number of samples above the NIOSH recommended exposure limit (REL); ppb=parts per billion; N/A indicates that NIOSH RELs are specified for personal air samples, and cannot be directly applied to area air samples; "-“ indicates that there is currently no REL for 2,3 -hexanedione. 
Table A2. OSHA Methods 1013/1016 full-shift average personal and area air sampling results by location Facility B, NIOSH industrial hygiene survey, May 2016.

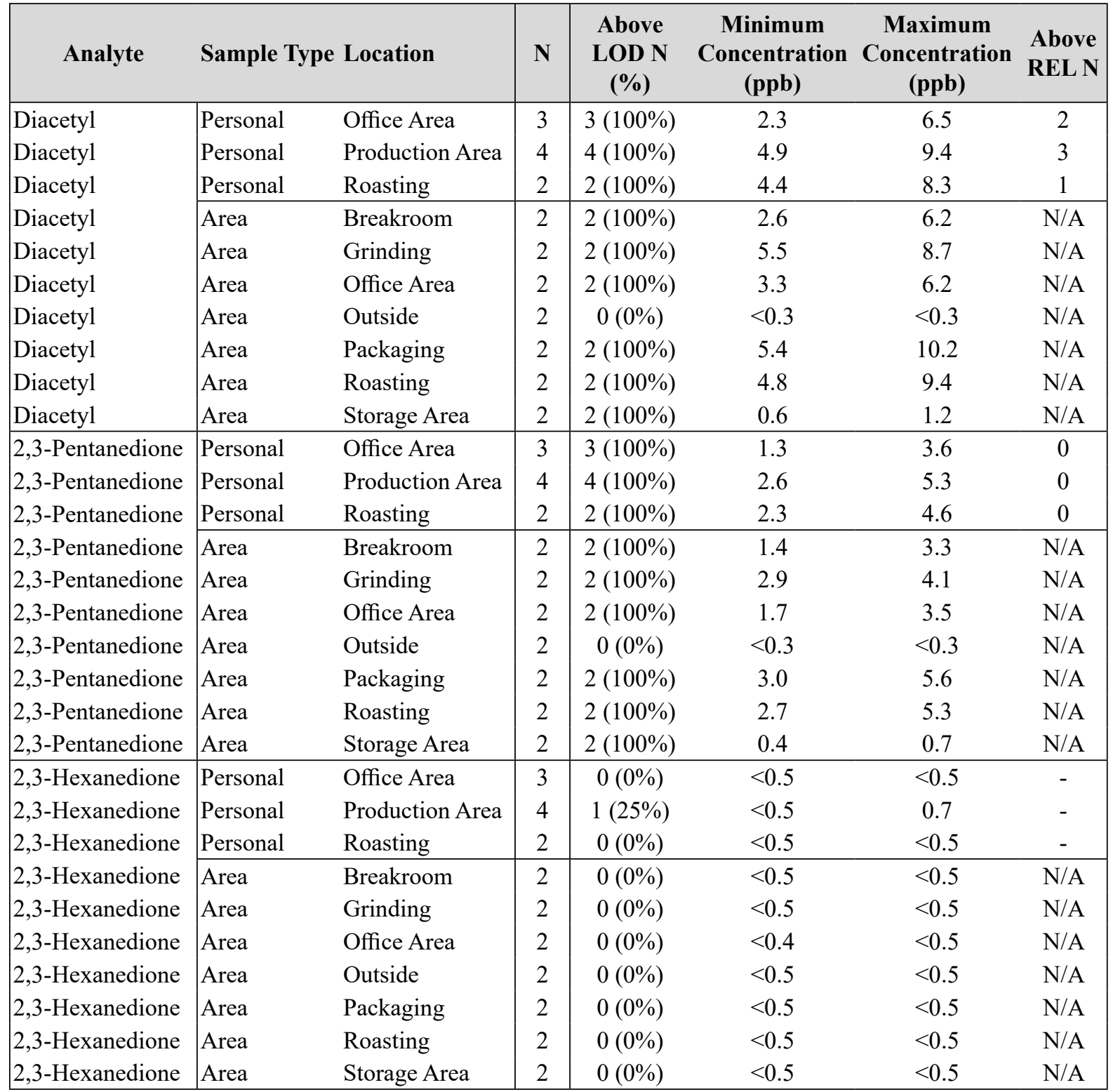

Note: OSHA=Occupational Safety and Health Administration; NIOSH=National Institute for Occupational Safety and Health; $N=$ number of samples; Above LOD N $(\%)=$ number and percentage of samples above limit of detection (LOD); < indicates below the limit of detection; Above REL N=number of samples above the NIOSH recommended exposure limit (REL); ppb=parts per billion; N/A indicates that NIOSH RELs are specified for personal air samples, and cannot be directly applied to area air samples; "_" indicates that there is currently no REL for 2,3-hexanedione. 
Table A3. OSHA Methods 1013/1016 personal task-based air sampling results, Facility A NIOSH industrial hygiene survey, May 2016.

\begin{tabular}{|c|c|c|c|c|c|c|}
\hline Analyte & Task & $\mathbf{N}$ & $\begin{array}{c}\text { Above } \\
\text { LOD N } \\
(\%)\end{array}$ & $\begin{array}{c}\text { Minimum } \\
\text { Concentration } \\
\text { (ppb) }\end{array}$ & $\begin{array}{c}\text { Maximum } \\
\text { Concentration } \\
(\text { ppb })\end{array}$ & $\begin{array}{l}\text { Mean (minutes) } \\
\text { Sample Duration } \\
\text { (range) }\end{array}$ \\
\hline Diacetyl & Cleaning Roaster & 1 & $0(0 \%)$ & $<2.1$ & $<2.1$ & 7 \\
\hline Diacetyl & Grind coffee beans & 3 & $3(100 \%)$ & 20.0 & 60.2 & $15(14-15)$ \\
\hline Diacetyl & Move roasted beans or ground coffee & 2 & $2(100 \%)$ & 38.3 & 52.4 & $15(14-15)$ \\
\hline Diacetyl & Package coffee & 4 & $4(100 \%)$ & 4.4 & 33.4 & $15(14-15)$ \\
\hline Diacetyl & Roast coffee beans & 4 & $4(100 \%)$ & 3.1 & 27.8 & $15(14-15)$ \\
\hline 2,3-Pentanedione & Cleaning Roaster & 1 & $0(0 \%)$ & $<2.1$ & $<2.1$ & 7 \\
\hline 2,3-Pentanedione & Grind coffee beans & 3 & $3(100 \%)$ & 14.1 & 41.4 & $15(14-15)$ \\
\hline 2,3-Pentanedione & Move roasted beans or ground coffee & 2 & $2(100 \%)$ & 24.0 & 32.5 & $15(14-15)$ \\
\hline 2,3-Pentanedione & Package coffee & 4 & $4(100 \%)$ & 1.1 & 19.6 & $15(14-15)$ \\
\hline 2,3-Pentanedione & Roast coffee beans & 4 & $4(100 \%)$ & 1.8 & 18.6 & $15(14-15)$ \\
\hline 2,3-Hexanedione & Cleaning Roaster & 1 & $0(0 \%)$ & $<3.1$ & $<3.1$ & 7 \\
\hline 2,3-Hexanedione & Grind coffee beans & 3 & $2(67 \%)$ & $<1.5$ & 2.9 & $15(14-15)$ \\
\hline 2,3-Hexanedione & Move roasted beans or ground coffee & 2 & $1(50 \%)$ & $<1.4$ & 2.0 & $15(14-15)$ \\
\hline 2,3-Hexanedione & Package coffee & 4 & $0(0 \%)$ & $<1.5$ & $<1.5$ & $15(14-15)$ \\
\hline 2,3-Hexanedione & Roast coffee beans & 4 & $0(0 \%)$ & $<1.4$ & $<1.5$ & $15(14-15)$ \\
\hline
\end{tabular}

Note: OSHA=Occupational Safety and Health Administration; NIOSH=National Institute for Occupational Safety and Health; N=number of samples; Above LOD N (\%) = number and percentage of samples above the limit of detection (LOD); < indicates below the LOD; ppb=parts per billion.

Table A4. OSHA Methods 1013/1016 personal task-based air sampling results, Facility B NIOSH industrial hygiene survey, May 2016.

\begin{tabular}{|c|c|c|c|c|c|c|}
\hline Analyte & Task & $\mathbf{N}$ & $\begin{array}{l}\text { Above } \\
\text { LOD N } \\
(\%)\end{array}$ & $\begin{array}{c}\text { Minimum } \\
\text { Concentration } \\
\text { (ppb) }\end{array}$ & $\begin{array}{c}\text { Maximum } \\
\text { Concentration } \\
(\text { ppb) }\end{array}$ & $\begin{array}{c}\text { Mean (range) } \\
\text { Sample Duration } \\
\text { (minutes) }\end{array}$ \\
\hline Diacetyl & Grind coffee beans & 2 & $2(100 \%)$ & 6.5 & 17.9 & $10(7-13)$ \\
\hline Diacetyl & Package coffee & 3 & $3(100 \%)$ & 3.7 & 11.8 & $14(14-15)$ \\
\hline Diacetyl & Roast coffee beans & 4 & $4(100 \%)$ & 4.6 & 9.2 & $15(14-15)$ \\
\hline 2,3-Pentanedione & Grind coffee beans & 2 & $2(100 \%)$ & 3.7 & 10.4 & $10(7-13)$ \\
\hline 2,3-Pentanedione & Package coffee & 3 & $3(100 \%)$ & 2.5 & 7.4 & $14(14-15)$ \\
\hline 2,3-Pentanedione & Roast coffee beans & 4 & $4(100 \%)$ & 3.0 & 5.5 & $15(14-15)$ \\
\hline 2,3-Hexanedione & Grind coffee beans & 2 & $0(0 \%)$ & $<1.6$ & $<3.1$ & $10(7-13)$ \\
\hline 2,3-Hexanedione & Package coffee & 3 & $0(0 \%)$ & $<1.4$ & $<1.5$ & $14(14-15)$ \\
\hline 2,3-Hexanedione & Roast coffee beans & 4 & $0(0 \%)$ & $<1.4$ & $<1.5$ & $15(14-15)$ \\
\hline
\end{tabular}

Note: OSHA=Occupational Safety and Health Administration; NIOSH=National Institute for Occupational Safety and Health; $N=$ number of samples; Above LOD $N(\%)=$ number and percentage of samples above the limit of detection (LOD); < indicates below the LOD; ppb=parts per billion. 
Table A5. Instantaneous* evacuated canister breathing zone task air sampling concentration results, Facility B NIOSH industrial hygiene survey, May 2016.

\begin{tabular}{|l|ccc|}
\hline Task Description & $\begin{array}{c}\text { Diacetyl } \\
(\mathbf{p p b})\end{array}$ & $\begin{array}{c}\mathbf{2 , 3 - P e n t a n e d i o n e} \\
\mathbf{( p p b )}\end{array}$ & $\begin{array}{c}\mathbf{2 , 3 - H e x a n e d i o n e} \\
\text { (ppb) }\end{array}$ \\
\hline Emptying Cooled Beans & 15.0 & 11.8 & 1.0 \\
Grinding Custom Blend & 19.3 & 11.5 & 0.8 \\
Placing Beans in Final Bag & 15.7 & 14.7 & 1.0 \\
\hline
\end{tabular}

Note: NIOSH=National Institute for Occupational Safety and Health; $p p b=$ parts per billion.

*Sampling duration approximately 30 seconds; samples were collected by placing the inlet of the sampler in the employee's personal breathing zone as he/she performed work task to mimic exposure. 


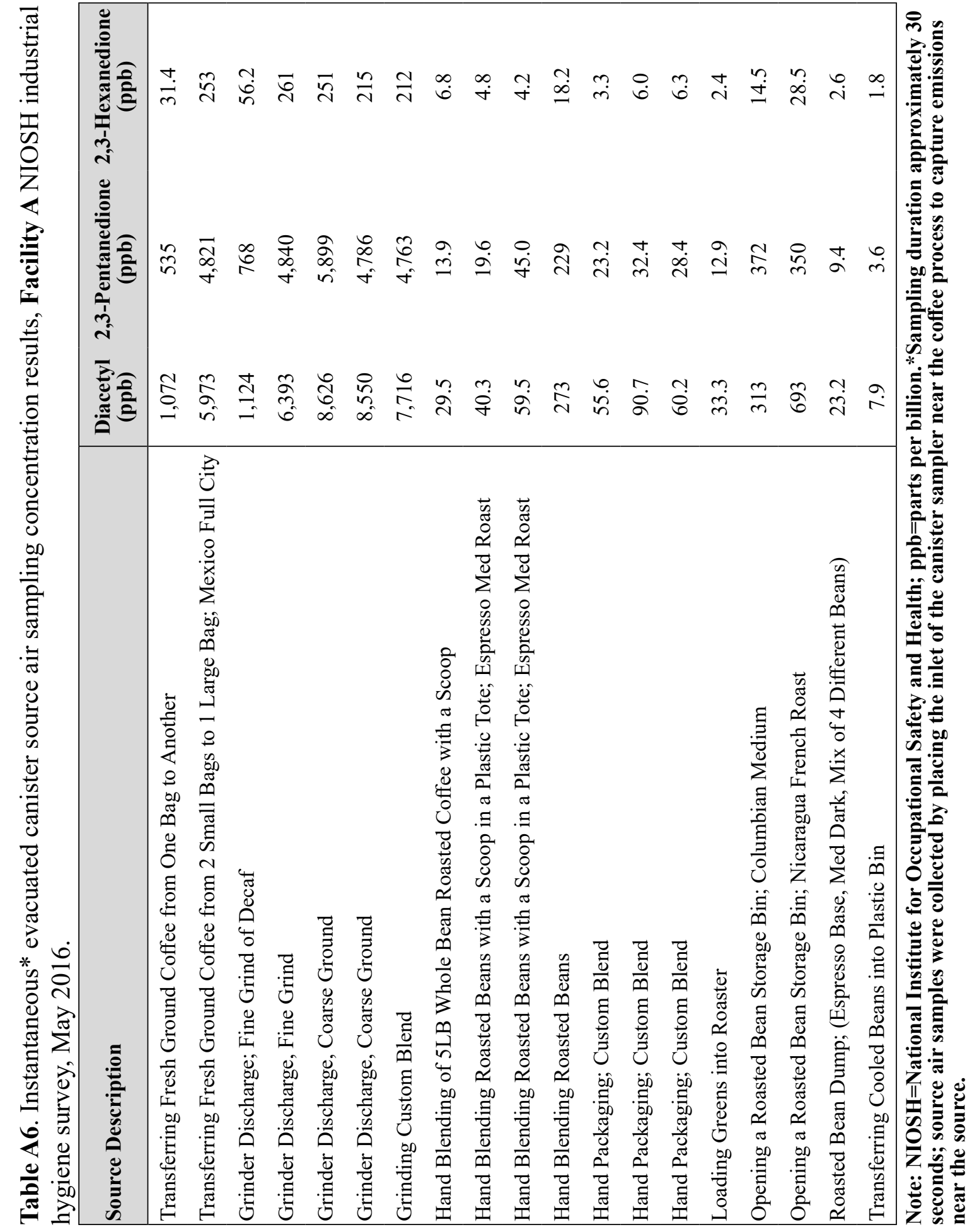


Table A7. Instantaneous evacuated canister source air sampling concentration results*, Facility B NIOSH industrial hygiene survey, May 2016.

\begin{tabular}{|l|ccc|}
\hline Source Description & $\begin{array}{c}\text { Diacetyl } \\
\text { (ppb) }\end{array}$ & $\begin{array}{c}\mathbf{2 , 3 - P e n t a n e d i o n e} \\
\text { (ppb) }\end{array}$ & $\begin{array}{c}\mathbf{2 , 3}-\text { Hexanedione } \\
\text { (ppb) }\end{array}$ \\
\hline Bag Sealer & 14.5 & 8.8 & $<0.9$ \\
Cooling Beans; Guatemala Blend & 5.7 & 2.3 & $<0.9$ \\
Transferring Beans into Final Bag; Custom Blend; Sampled at Top of Bag & 57.6 & 55.8 & 5.0 \\
Transferring Beans into Final Bag; Custom Blend; Sampled at Top of Bag & 105 & 59.0 & 12.3 \\
Grinding Custom Blend; Sample Taken on Back of Grinder at Grinder Vent & 48.3 & 23.8 & 1.9 \\
Grinding Custom Blend Decaf; Sampled at top of Bag; & 14,576 & 7,281 & 464 \\
Hand Packing Guatemala Full-City Roast Beans & 50.7 & 18.9 & 1.9 \\
Inside Decaf French Roast Storage Bin & 1,184 & 409 & 40.6 \\
Inside Decaf Full City Storage Bin & 1,085 & 419 & 33.8 \\
Inside Custom Blend Storage Bin; Roasted 10 minutes prior to sample & 42.0 & 19.2 & 11.3 \\
Inside Storage Bin; Custom Blend; Roasted 10 minutes prior to sample & 19.5 & 7.4 & 1.3 \\
Inside Box of Packaged Coffees; Various Blends/Roasts & 9.4 & 5.2 & 1.5 \\
Packing Bags of Coffee into Shipping Box & 6.6 & 2.8 & 0.9 \\
\hline
\end{tabular}

Note: NIOSH = National Institute for Occupational Safety and Health; $p p b=$ parts per billion. $*$ The roasted coffee beans in the bins off-gassing for different amounts of time, and this could be responsible for some of the differences in headspace analysis results.

Table A8. Bulk coffee sample results using headspace analysis from both facilities, NIOSH industrial hygiene survey, May 2016.

\begin{tabular}{|l|ccc|}
\hline Coffee/Roast Level & $\begin{array}{c}\mathbf{2 , 3 - B u t a n e d i o n e} \\
\mathbf{( p p b )}\end{array}$ & $\begin{array}{c}\mathbf{2 , 3 - P e n t a n e d i o n e} \\
\mathbf{( p p b )}\end{array}$ & $\begin{array}{c}\mathbf{2 , 3 - H e x a n e d i o n e} \\
\mathbf{( p p b )}\end{array}$ \\
\hline Black dog, French Roast & 3,422 & 1,576 & $<211$ \\
Espresso base, Med/Dark Roast & 1,670 & 1,146 & $<211$ \\
Guatemala, Full City Roast & 4,051 & 2,967 & 206 \\
Guatemala, Full City Roast & 2,870 & 1,122 & $<209$ \\
Nicaragua, French Roast & 1,676 & 1,033 & 224 \\
Noradino Decaf. Roast & 6,504 & 4,443 & $<210$ \\
Peru Decaf, Full City Roast & 8,902 & 4,994 & 253 \\
\hline
\end{tabular}

Note: NIOSH=National Institute for Occupational Safety and Health; ppb=parts per billion; < indicates below the limit of detection. 
Table A9. Prevalence of reported symptoms, NIOSH medical survey participants (N=11), May 2016.

\begin{tabular}{|c|c|c|}
\hline Symptom & $\begin{array}{c}\text { Experienced in the last } 12 \text { months } \\
\text { Number }(\%)\end{array}$ & $\begin{array}{l}\text { Experienced in the last } 4 \text { weeks } \\
\text { Number }(\%)\end{array}$ \\
\hline Nose symptoms* & $8(73 \%)$ & $2(18 \%)$ \\
\hline Eye symptoms $\dagger$ & $5(45 \%)$ & $3(27 \%)$ \\
\hline Sinusitis or sinus problems & $3(27 \%)$ & 0 \\
\hline Problem with ability to smell & 0 & - \\
\hline Phlegm on most days for 3 months & 0 & - \\
\hline $\begin{array}{l}\text { Lower respiratory symptoms (reported at least one } \\
\text { of the following) }\end{array}$ & $4(36 \%)$ & $3(27 \%)$ \\
\hline Chest wheezing or whistling & $2(18 \%)$ & $2(18 \%)$ \\
\hline Usual cough $\dagger \dagger$ & 0 & - \\
\hline SOB on level ground or walking up a slight a hilli† & $3(27 \%)$ & - \\
\hline Breathing trouble & $4(36 \%)$ & $2(18 \%)$ \\
\hline Awoke with chest tightness & 0 & - \\
\hline Asthma attack & 0 & - \\
\hline Awoke with shortness of breath & $2(18 \%)$ & 0 \\
\hline $\begin{array}{l}\text { Systemic symptoms (reported at least one of the } \\
\text { following) }\end{array}$ & $4(36 \%)$ & $3(27 \%)$ \\
\hline Flu-like achiness or achy joints & $1(9 \%)$ & $1(9 \%)$ \\
\hline Fever or chills & 0 & - \\
\hline Unusual tiredness or fatigue & $3(27 \%)$ & $2(18 \%)$ \\
\hline
\end{tabular}

Note: $N=$ number of participants; $\mathrm{SOB}=$ shortness of breath; "“_" = A four week question was not asked for the symptom.*Nose symptoms includes one or both of the following: 1) stuffy, itchy, or runny nose or 2) stinging, burning nose. $\dagger$ Eye symptoms includes one or both of the following: 1) watery, itchy eyes or 2) stinging, burning eyes. $\dagger \uparrow$ Symptom question did not specify last 12 months.

Table A10. Adjusted* comparisons of symptoms and self-reported physician diagnosis among NIOSH medical survey participants $(\mathrm{N}=11)$ to U.S. adult population May 2016.

\begin{tabular}{|l|l|c|c|c|}
\hline Health condition & $\begin{array}{l}\text { Comparative } \\
\text { population }\end{array}$ & $\begin{array}{c}\text { Observed } \\
\text { Number }\end{array}$ & $\begin{array}{c}\text { Expected } \\
\text { Number }\end{array}$ & $\begin{array}{c}\text { SMR } \\
(95 \% \mathrm{CI})\end{array}$ \\
\hline Watery, itchy eyes last 12 months & NHANES III & 5 & 4.3 & $1.2(0.5-2.7)$ \\
\hline Stuffy, itchy, or runny nose last 12 months & NHANES III & 8 & 6.0 & $1.3(0.7-2.6)$ \\
\hline Sinus problems last 12 months & NHANES III & 3 & 3.7 & $0.8(0.3-2.4)$ \\
\hline Wheeze last 12 months & NHANES 2007-2012 & 2 & 1.6 & $1.2(0.3-4.5)$ \\
\hline Shortness of breath on exertion & NHANES III & 3 & 2.0 & $1.5(0.5-4.4)$ \\
\hline Ever asthma (physician-diagnosed) & NHANES 2007-2012 & 2 & 0.8 & $2.5(0.7-9.2)$ \\
\hline Current asthma (physician-diagnosed) & NHANES 2007-2012 & $\mathbf{2}^{\mathbf{\beta}}$ & $\mathbf{0 . 5}$ & $\mathbf{4 . 1 ( 1 . 1 - 1 4 . 9 )}$ \\
\hline
\end{tabular}

Note: NHANES=National Health and Nutrition Survey; SMR= standardized morbidity ratio.

*Adjusted for sex, race/ethnicity, age, and smoking categories. $†$ We used the most recent NHANES survey available for each comparison. $\$ 95 \%$ confidence intervals (CIs) that exclude 1.0 are statistically significantly different from comparison with US adult population and are shown in bold. $\beta$ Both participants reported that their asthma developed before they began working at the coffee production facilities. 


\section{References}

ACGIH (American Conference of Governmental Industrial Hygienists) [2017a]. 2017 TLVs ${ }^{\circledR}$ and BEIs ${ }^{\circledR}$ : Threshold limit values for chemical substances and physical agents and biological exposure indices. Cincinnati, $\mathrm{OH}$ : American Conference of Governmental Industrial Hygienists.

ACGIH [2017b]. Chemicals substances and other issues under study (TLV $\left.{ }^{\circledR}-\mathrm{CS}\right)$. [http://www.acgih.org/tlv-bei-guidelines/documentation-publications-and-data/under-study-

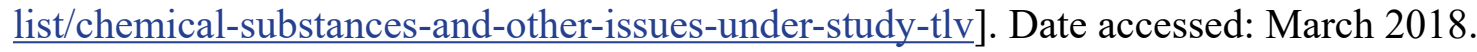

Akiyama M, Murakami K, Ohtani N, Iwatsuki K, Sotoyama K, Wada A, Tokuno K, Iwabuchi $\mathrm{H}$, Tanaka K [2003]. Analysis of volatile compounds released during the grinding of roasted coffee beans using solid-phase microextraction. J Agric Food Chem 51(7):1961-1969.

Akpinar-Elci M, Travis WD, Lynch DA, Kreiss K [2004]. Bronchiolitis obliterans syndrome in popcorn production plant workers. Eur Respir J 24(2):298-302.

Anderson BA, Shimoni E, Liardon R, Labuza P [2003]. The diffusion kinetics of carbon dioxide in fresh roasted and ground coffee. J Food Eng 59:71-78.

ANSI (American National Standards Institute)/ASHRAE [2016]. Ventilation for acceptable indoor air quality, standard 62.1-2016. Atlanta, GA: ASHRAE.

Bailey RL, Cox-Ganser JM, Duling MG, LeBouf RF, Martin SB Jr, Bledsoe TA, Green BJ, Kreiss K [2015]. Respiratory morbidity in a coffee processing workplace with sentinel obliterative bronchiolitis cases. Am J Ind Med 58(12):1235-1245.

Berger KI, Reibman J, Oppenheimer BW, Vlahos I, Harrison D, Goldring RM [2013]. Lessons from the World Trade Center disaster: airway disease presenting as restrictive dysfunction. Chest 144(1):249-257.

Burney PG, Laitinen LA, Perdrizet S, Huckauf H, Tattersfield AE, Chinn S, Poisson N, Heeren A, Britton JR, Jones T [1989]. Validity and repeatability of the IUATLD (1984) bronchial symptoms questionnaire: an international comparison. Eur Respir J 2(10):940-945.

Burney PGJ, Chinn S [1987]. Developing a new questionnaire for measuring the prevalence and distribution of asthma. Chest 91(6 Suppl):79S-83S.

Burney PGJ, Luczynska C, Chinn S, Jarvis D [1994]. The European community respiratory health survey. Eur Respir J 7(5):954-960. 
CDC (Centers for Disease Control and Prevention) [1996]. Third National Health and Nutrition Examination Survey, 1988-1994, NHANES III Examination Data File [CDROM]. Hyattsville, Maryland: U.S. Department of Health and Human Services, Centers for Disease Control and Prevention. (Public use data file documentation No. 76300.)

CDC [2013a]. Carbon monoxide [https://www.cdc.gov/niosh/topics/co-comp/default.html]. Date accessed: February 2018.

CDC [2013b]. Obliterative bronchiolitis in workers in a coffee-processing facility-Texas, 2008-2012. Morb Mortal Wkly Rep 62(16):305-307.

CDC [2017]. Smoking \& tobacco use: quit smoking [https://www.cdc.gov/tobacco/stateandcommunity/tobacco control_programs/index.htm]. Date accessed: March 2018.

CDC [2019]. National Center for Health Statistics. National Health and Nutrition Examination Survey Data. Hyattsville, MD: U.S. Department of Health and Human Services, Centers for Disease Control and Prevention, [2007-2012] Available at: https://wwwn.cdc. gov/nchs/nhanes/default.aspx. Date accessed: March 2018.

CFR. Code of Federal Regulations. Washington, DC: U.S. Government Printing Office, Office of the Federal Register.

Daglia M, Papetti A, Aceti C, Sordelli B, Spini V, Gazzani G [2007]. Isolation and determination of $\alpha$-dicarbonyl compounds by RP-HPLC-DAD in green and roasted coffee. $\mathrm{J}$ Agric and Food Chem 55(22):8877-8882.

Day G, LeBouf R, Grote A, Pendergrass S, Cummings K, Kreiss K, Kullman G [2011]. Identification and measurement of diacetyl substitutes in dry bakery mix production. J Occup Environ Hyg 8(2):93-103.

de Assumpção MS, Gonçalves RM, Martins R, Bobbio TG, Schivinski CI [2016]. Reference Equations for Impulse Oscillometry System Parameters in Healthy Brazilian Children and Adolescents. Respir Care 61(8):1090-1099.

Desiraju K, Agrawal A [2016]. Impulse oscillometry: The state-of-art for lung function testing. Lung India 33(4):410-416.

Duling MG, LeBouf RF, Cox-Ganser JM, Kreiss K, Martin SB Jr, Bailey RL [2016]. Environmental characterization of a coffee processing workplace with obliterative bronchiolitis in former workers. J Occup Environ Hyg 13(10):770-781.

Dweik RA, Boggs PB, Erzurum SC, Irvin CG, Leigh MW, Lundberg JO, Olin AC, Plummer AL, Taylor DR; American Thoracic Society Committee on Interpretation of Exhaled Nitric Oxide Levels (FENO) for Clinical Applications [2011]. An official ATS clinical practice 
guideline: interpretation of exhaled nitric oxide levels (FENO) for clinical applications. Am J Respir Crit Care Med 184(5):602-615.

EAACI Task Force on Occupational Rhinitis, Moscato G, Vandenplas O, Gerth Van Wijk R, Malo JL, Quirce S, Walusiak J, Castano R, De Groot H, Folletti I, Gautrin D, Yacoub MR, Perfetti L, Siracusa A [2008]. Occupational rhinitis. Allergy 63(8):969-980.

ECRHS (European Community Respiratory Health Survey) [2014]. Questionnaires, protocols and instructions. [http://www.ecrhs.org/Quests.htm]. Date accessed: March 2018.

Ferris BG [1978]. Epidemiology standardization project. AmRev Respir Dis 118(Suppl):1-53.

Figley KD, Rawling FF [1950] Castor bean: an industrial hazard as a contaminant of green coffee dust and used burlap bags. J Allergy 21:545-553.

Hankinson JL, Odencrantz JR, Fedan KB [1999]. Spirometric reference values from a sample of the general U.S. population. Am J Respir Crit Care Med 159(1):179-187.

Henneberger PK Redlich CA, Callahan DB, Harber P, Lemière C, Martin J, Tarlo SM, Vandenplas O, Torén K; ATS Ad Hoc Committee on Work-Exacerbated Asthma [2011]. An official American Thoracic Society statement: work-exacerbated asthma. Am J Respir Crit Care Med 184(3):368-378.

Hubbs AF, Cumpston AM, Goldsmith WT, Battelli LA, Kashon ML, Jackson MC, Frazer DG, Fedan JS, Goravanahally MP, Castranova V, Kreiss K, Willard PA, Friend S, SchweglerBerry D, Fluharty KL, Sriram K [2012]. Respiratory and olfactory cytotoxicity of inhaled 2,3-pentanedione in Sprague-Dawley rats. Am J Pathol 181(3):829-844.

Kanwal R, Kullman G, Piacitelli C, Boylstein R, Sahakian N, Martin S, Fedan K, Kreiss K [2006]. Evaluation of flavorings-related lung disease risk at six microwave popcorn plants. J Occup Environ Med. 48(2):149-57.

Karr RM, Davies RJ, Butcher BT, Lehrer SB, Wilson MR, Dharmarajan V, Salvaggio JE [1978]. Occupational asthma. J Allergy Clin Immunol 61(1):54-65.

Kim TJ, Materna BL, Prudhomme JC, Fedan KB, Enright PL, Sahakian NM, Windham GC, Kreiss K [2010]. Industry-wide medical surveillance of California flavor manufacturing workers: Cross-sectional results. Am J Ind Med 53(9):857-865.

King MS, Eisenberg R, Newman JH, Tolle JJ, Harrell FE Jr, Nian H, Ninan M, Lambright ES, Sheller JR, Johnson JE, Miller RF [2011]. Constrictive bronchiolitis in soldiers returning from Iraq and Afghanistan. N Engl J Med. 365(3):222-230. 
Komarow HD, Myles IA, Uzzaman A, Metcalfe DD [2011]. Impulse oscillometry in the evaluation of diseases of the airways in children. Ann Allergy Asthma Immunol 106(3):191199.

Kreiss K [2013]. Occupational causes of constrictive bronchiolitis. Curr Opin Allergy Clin Immunol 13(2):167-72.

Langford NJ [2005]. Carbon dioxide poisoning. Toxicol Rev 24(4):229-235.

LeBouf RF, Stefaniak AB, Virji, MA [2012]. Validation of evacuated canisters for sampling volatile organic compounds in healthcare settings. J Environ Monit 14(3):977-983.

LeBouf RF and Simmons M [2017]. Increased sensitivity of OSHA method analysis of diacetyl and 2,3-pentanedione in air. J Occup Environ Hyg 14(5):343-348.

Lee JY, Seo JH, Kim HY, Jung YH, Kwon JW, Kim BJ, Kim HB, Lee SY, Jang GC, Song DJ, Kim WK, Shim JY, Kim HJ, Shin YJ, Park JW, Cho SH, Lee JS, Hong SJ [2012]. Reference values of impulse oscillometry and its utility in the diagnosis of asthma in young Korean children. J Asthma 49(8):811-816.

Lehrer SB, Karr RM, Salvaggio JE [1978]. Extraction and analysis of coffee bean allergens. Clin Allergy 8(3):217-226.

Malmberg LP, Pelkonen A, Poussa T, Pohianpalo A, Haahtela T, Turpeinen M [2002]. Determinants of respiratory system input impedance and bronchodilator response in healthy Finnish preschool children. Clin Physiol Funct Imaging 22(1):64-71.

Miller MR, Hankinson J, Brusasco V, Burgos F, Casaburi R, Coates A, Crapo R, Enright P, van der Grinten CP, Gustafsson P, Jensen R, Johnson DC, MacIntyre N, McKay R, Navajas D, Pedersen OF, Pellegrino R, Viegi G, Wanger J, ATS/ERS Task Force [2005]. Standardisation of spirometry. Eur Respir J 26(2):319-338.

Morgan DL, Jokinen MP, Price HC, Gwinn WM, Palmer SM, Flake GP [2012]. Bronchial and bronchiolar fibrosis in rats exposed to 2,3-pentanedione vapors: implications for bronchiolitis obliterans in humans. Toxicol Pathol 40(3):448-465.

Morgan DL, Jokinen MP, Johnson CL, Price HC, Gwinn WM, Bousquet RW, Flake GP [2016]. Chemical reactivity and respiratory toxicity of the $\alpha$-diketone flavoring agents: 2,3-butanedione, 2,3-pentanedione, and 2,3-hexanedione. Toxicol Pathol 44(5):763-783.

Newbury W, Crockett A, Newbury J [2008]. A pilot study to evaluate Australian predictive equations for the impulse oscillometry system. Respirology 13(7):1070-1075.

Newton J [2002]. Carbon monoxide exposure from coffee roasting. Appl Occup Environ Hyg. 17(9):600-602. 
NIOSH (National Institute for Occupational Safety and Health) [2010]. NIOSH pocket guide to chemical hazards. Cincinnati, OH: U.S. Department of Health and Human Services, Centers for Disease Control and Prevention, National Institute for Occupational Safety and Health, DHHS (NIOSH) Publication No. 2010-168c. [http://www.cdc.gov/niosh/npg/]. Date accessed: March 2018.

NIOSH [2012]. Flavoring-related lung disease. Information for healthcare providers. Department of Health and Human Services, Centers for Disease Control and Prevention, DHHS (NIOSH) Publication No. 2012-148 (supersedes 2012-107). [http://www.cdc.gov/ niosh/docs/2012-148/]. Date accessed: March 2018.

NIOSH [2016]. Criteria for a recommended standard: occupational exposure to diacetyl and 2,3-pentanedione. U.S. Department of Health and Human Services, Centers for Disease Control and Prevention, National Institute for Occupational Safety and Health, DHHS (NIOSH) Publication No. 2016-111. [https://www.cdc.gov/niosh/docs/2016-111/]. Date accessed: March 2018.

Nishimura F, Abe S, Fukunaga T [2003]. Carbon monoxide poisoning from industrial coffee extraction. JAMA 290(3):334.

NYCDH\&MH (New York City Department of Health and Mental Hygiene) [2008]. Guidelines on assessment and remediation of fungi in indoor environments [http://www1.nyc.gov/assets/doh/downloads/pdf/epi/epi-mold-guidelines.pdf]. Date accessed: March 2018.

Oldenburg M, Bittner C, Baur X [2009]. Health risks due to coffee dust. Chest 136(2):536544.

Oppenheimer BW, Goldring RM, Herberg ME, Hofer IS, Reyfman PA, Liautaud S, Rom WN, Reibman J, Berger KI [2007]. Distal airway function in symptomatic subjects with normal spirometry following World Trade Center dust exposure. Chest 132(4):1275-1282.

OSHA (Occupational Safety and Health Administration) [1993]. Compliance and Enforcement Activities Affected by the PELs Decision. August 5, 1993 Memorandum. [https://www.osha.gov/pls/oshaweb/owadisp.show document?p $\underline{\text { table}=I N T E R P R E T A T I O N S \& p ~ i d=21220] . ~ D a t e ~ a c c e s s e d: ~ M a r c h ~} 2018$.

OSHA [2003]. Enforcement policy for respiratory hazards not covered by OSHA permissible exposure limits. January 24, 2003 Memorandum. [https://www.osha.gov/pls/oshaweb/ owadisp.show document?p table=INTERPRETATIONS\&p_id=24749]. Date accessed: March 2018.

OSHA [2008]. Sampling and analytical methods: Method 1013 - Acetoin and diacetyl. [http://www.osha.gov/dts/sltc/methods/validated/1013/1013.html]. Date accessed: March 2018. 
OSHA [2010]. Sampling and analytical methods: Method 1016 - 2,3-pentanedione. [http:// www.osha.gov/dts/sltc/methods/validated/1016/1016.html]. Date accessed: March 2018.

OSHA [2014]. OSHA Fact Sheet: Do you have work-related asthma? A guide for you and your doctor. Washington, D.C.: U.S. Department of Labor, Occupational Safety and Health Administration. [https://www.osha.gov/Publications/OSHA3707.pdf]. Date accessed: March 2018.

OSHA [2017]. Permissible exposure limits - annotated tables. [https://www.osha.gov/dsg/ annotated-pels/index.html]. Date accessed: March 2018.

Park JH, Yoon JW, Shin YH, Jee HM, Wee YS, Chang SJ, Sim JH, Yum HY, Han MY [2011]. Reference values for respiratory system impedence using impulse oscillometry in healthy preschool children. Korean J Pediatr 54(2)64-68.

Pellegrino R, Viegi G, Brusasco V, Crapo RO, Burgos F, Casaburi R, Coates A, van der Grinten CP, Gustafsson P, Hankinson J, Jensen R, Johnson DC, MacIntyre N, McKay R, Miller MR, Navajas D, Pedersen OF, Wanger J [2005]. Interpretative strategies for lung function tests. Eur Respir J 26(5):948-968.

Raffel JB, Thompson J [2013]. Carbon monoxide from domestic coffee roasting: a case report. Ann Intern Med 159(11):795-796.

Rondón C, Campo P, Galindo L, Blanca-López N, Cassinello MS, Rodriguez-Bada JL, Torres MJ, Blanca M [2012]. Prevalence and clinical relevance of local allergic rhinitis. Allergy 67(10):1282-1288.

Rondón C, Bogas G, Barrionuevo E, Blanca M, Torres MJ, Campo P [2017]. Nonallergic rhinitis and lower airway disease. Allergy 72(1):24-34.

Rose JJ, Wang L, Xu Q, McTiernan CF, Shiva S, Tejero J, Gladwin MT [2017]. Carbon monoxide poisoning: pathogenesis, management, and future directions of therapy. Am J Respir Crit Care Med 195(5):596-606.

Sahay S, Gera K, Bhargava SK, Shah A [2016]. Occurrence and impact of sinusitis in patients with asthma and/or allergic rhinitis. J Asthma 53(6):635-643.

Schulz H, Flexeder C, Behr J, Heier M, Holle R, Huber RM, Jörres RA, Nowak D, Peters A, Wichmann HE, Heinrich J, Karrasch S; KORA Study Group [2013]. Reference values of impulse oscillometric lung function indices in adults of advanced age. PLoS ONE 15;8(5):e63366. doi: 10.1371/journal.pone.0063366.

Schulze J, Biedebach S, Christmann M, Herrmann E, Voss S, Zielen S [2016]. Impulse Oscillometry as a Predictor of Asthma Exacerbations in Young Children. Respiration 91(2):107-114. 
Shaaban R, Zureik M, Soussan D, Neukirch C, Heinrich J, Sunyer J, Wjst M, Cerveri I, Pin I, Bousquet J, Jarvis D, Burney PG, Neukirch F, and Leynaert B [2008]. Rhinitis and onset of asthma: a longitudinal population-based study. Lancet 372(9643):1049-1057.

Shi Y, Aledia AS, Tatavoosian AV, Vijayalakshmi S, Galant SP, George SC [2012]. Relating small airways to asthma control by using impulse oscillometry in children.

Allergy Clin Immunol 129(3):671-678.

Smith HJ, Reinhold P, Goldman MD [2005]. Forced oscillation technique and impulse oscillometry. In: Gosselink R, Stam H, eds. European Respiratory Monograph 31: Lung Function Testing. Vol. 10. Wakefield, UK: European Respiratory Society Journals, pp. 72 105.

Smith HJ (Hans-Juergen.Smith@CareFusion.com) [2015]. Questions about impulse oscillometry. Email of December 9, 2015, from Hans-Juergen Smith, CareFusion, to Rachel Bailey (feu2@cdc.gov), Respiratory Health Division, National Institute for Occupational Safety and Health, Centers for Disease Control and Prevention, Department of Health and Human Services.

Song TW, Kim KW, Kim ES, Park JW, Sohn MH, Kim KE [2008]. Utility of impulse oscillometry in young children with asthma. Pediatr Allergy Immunol 19(8):763-768.

Tarlo SM, Lemiere C [2014]. Occupational asthma. N Engl J Med 370:640-649.

Tarlo SM [2016].Update on work-exacerbated asthma. Int J Occup Med Environ Health 29(3):369-374.

Thomas KE, Trigg CJ, Baxter PJ, Topping M, Lacey J, Crook B, Whitehead P, Bennett JB, Davies RJ. 1991. Factors relating to the development of respiratory symptoms in coffee process workers. Br J Ind Med 48(5):314-322.

Vogel J, Smidt U [1994] Impulse oscillometry analysis of lung mechanics in general practice and clinic, epidemiological and experimental research. $1^{\text {st }}$ ed. Frankfurt: PMI-Verlagsgruppe.

Weinstein DJ, Hull JE, Ritchie BL, Hayes JA, Morris MJ [2016]. Exercise-associated excessive dynamic airway collapse in military personnel. Ann Am Thorac Soc 13(9):14761482.

Zuskin E, Valić F, Skurić Z [1979]. Respiratory function in coffee workers. Br J Ind Med 36(2):117-122.

Zuskin E, Kanceljak B, Skurić Z, Butković D [1985]. Bronchial reactivity in green coffee exposure. Br J Ind Med 42(6):415-420. 
This page left intentionally blank 
Keywords: NAICS 311920 (Coffee roasting), Georgia, Florida, diacetyl, 2,3-pentanedione, 2,3-hexanedione, coffee, carbon monoxide, carbon dioxide, volatile organic compounds (VOCs). 
The Health Hazard Evaluation Program investigates possible health hazards in the workplace under the authority of the Occupational Safety and Health Act of 1970 (29 U.S.C. § 669(a)(6)). The Health Hazard Evaluation Program also provides, upon request, technical assistance to federal, state, and local agencies to investigate occupational health hazards and to prevent occupational disease or injury. Regulations guiding the Program can be found in Title 42, Code of Federal Regulations, Part 85; Requests for Health Hazard Evaluations (42 CFR Part 85).

\section{Disclaimer}

The recommendations in this report are made on the basis of the findings at the workplace evaluated and may not be applicable to other workplaces.

Mention of any company or product in this report does not constitute endorsement by the National Institute for Occupational Safety and Health (NIOSH).

Citations to Web sites external to NIOSH do not constitute NIOSH endorsement of the sponsoring organizations or their programs or products. NIOSH is not responsible for the content of these Web sites. All Web addresses referenced in this document were accessible as of the publication date.

\section{Acknowledgments}

Desktop Publisher: Tia McClelland

Data Analysis Support: Nicole Edwards, Kathleen Fedan, and Brian Tift

Laboratory Support: Dru Burns, Kyle Hatcher, Ryan LeBouf, Anand Ranpara

Site Visit Team Members: Matthew Duling, Marcia Stanton, Robert Lawrence, Tia McClelland, Randall Nett, and Michael Beaty

\section{Availability of Report}

Copies of this report have been sent to the employer and employees at the facility. The state health department and the Occupational Safety and Health Administration Regional Office have also received a copy. This report is not copyrighted and may be freely reproduced.

This report is available at http://www.cdc.gov/niosh/hhe/reports/pdfs/2016-0006-3309.pdf.

All other Health Hazard Evaluation Reports may be found at http://www2a.cdc.gov/hhe/search.asp.

\section{Recommended citation for this report:}

$\mathrm{NIOSH}$ [2018]. Health hazard evaluation report: Evaluation of exposures and respiratory health at two coffee roasting and packaging facilities. By Duling MG, Harvey RR, Stanton ML, Lawrence RB, McClelland TL, and Nett RJ, MD. Morgantown, WV: U.S. Department of Health and Human Services, Centers for Disease Control and Prevention, National Institute for Occupational Safety and Health, NIOSH HHE Report No. 2016-006-3309. 
Delivering on the Nation's promise:

Safety and health at work for all people through research and prevention

To receive documents or other information about occupational safety and health topics, contact NIOSH

Telephone: 1-800-CDC-INFO (1-800-232-4636)

TTY: 1-888-232-6348

email: cdcinfo@cdc.gov

or visit the NIOSH website at http://www.cdc.gov/niosh

SAFER • HEALTHIER $\cdot$ PEOPLE $^{\text {TM }}$ 